\title{
Plantas e constituintes químicos empregados em Odontologia: revisão de estudos etnofarmacológicos e de avaliação da atividade antimicrobiana in vitro em patógenos orais
}

VIEIRA, D.R.P. ${ }^{1 *}$; AMARAL, F.M.M. ${ }^{2}$; MACIEL, M.C.G. ${ }^{3}$; NASCIMENTO, FLÁVIA F.R.F. ${ }^{3}$; LIBÉRIO, A.S. ${ }^{4}$. ${ }^{1 *}$ Universidade Federal do Maranhão, Campus do Bacanga, Av. dos Portugueses s/n, 65085-580, São Luís, Maranhão, Brasil. Autor para correspondência: End: Av. 03, Q-29, n²3. Ipem São Cristóvão. CEP: 65056-020. Fone: (98) 3245-3821. E-mail: deniserpvieira@gmail.com; ${ }^{2}$ Departamento de Farmácia, Universidade Federal do Maranhão, Campus do Bacanga, Av. dos Portugueses s/n, 65085-580, São Luís, Maranhão, Brasil; ${ }^{3}$ Laboratório de Imunofisiologia, Universidade Federal do Maranhão, Campus do Bacanga, Av. dos Portugueses s/n, 65085580, São Luís, Maranhão, Brasil; ' ${ }^{4}$ Departamento de Odontologia, Universidade Federal do Maranhão, Campus do Bacanga, Av. dos Portugueses s/n, 65085-580, São Luís, Maranhão, Brasil.

RESUMO: Produtos derivados de plantas podem representar estratégia promissora na odontologia. Desse modo, o objetivo deste trabalho foi levantar na literatura os estudos sobre o uso popular de plantas em afecções orais, bem como os estudos de avaliação da atividade antimicrobiana in vitro de extratos vegetais e compostos isolados sobre patógenos orais, no período de 1996 a 2011. Quarenta e sete famílias botânicas foram referidas, com maior número de citações para Anacardiaceae, sendo Anacardium occidentale L., a espécie mais citada. O levantamento sobre estudos de avaliação antimicrobiana relacionou extratos de sessenta e seis espécies vegetais pertencentes a trinta e oito famílias botânicas, destacando-se Anacardiaceae, com pesquisas realizadas de forma predominante com as folhas, investigadas pelo método de difusão em ágar. Cinquenta e oito substâncias isoladas de plantas foram avaliadas, demonstrando que Terminalia chebula Retz (Combretaceae) representa a espécie vegetal com atividade antimicrobiana in vitro mais significativa, apresentando halo de inibição de 32,97 mm contra Staphylococcus aureus, microrganismo encontrado em infecções orais; enquanto ácido tetra iso-alfa isolada de Humulus lupulus L. (Canabinaceae) apresentou maior halo de inibição para Streptococcus mutans $(26,0 \mathrm{~mm})$. Os resultados apresentados devem estimular o desenvolvimento dos estudos de validação na garantia do uso seguro e eficaz de espécies vegetais em odontologia.

Palavras-chave: Plantas medicinais, saúde bucal, infecções orais, in vitro, revisão.

ABSTRACT: Plants and chemical constituents used in dentistry: review of ethnopharmacological and antimicrobial activity studies in oral pathogens. Products derived from plants may represent a promising strategy in dentistry. Thus, the objective of this paper is to review studies of the popular use of plants in oral diseases, as well as studies evaluating the in vitro antimicrobial activity of plant extracts and isolated compounds in oral pathogens from 1996 to 2011. Forty-seven botanical families were mentioned, with the highest number of referencesfor Anacardiaceae, and Anacardium occidentale L. was the most mentioned specie. The review of antimicrobial activity studies relatedextracts from sixty-six plant species belonging to thirty-eight botanical families, especially Anacardiaceae, being predominant tests with leaves, investigated by the agar diffusion method. Fifty-eight compounds isolated from plants have been evaluated, showing that Terminalia chebula Retz (Combretaceae) represents the plant species with more meaningful in vitro antimicrobial activity, with inhibition zone of $32.97 \mathrm{~mm}$ against Staphylococcus aureus, microorganism found in oral infections, while tetra iso-alpha acid isolated from Humulus lupulus L. (Canabinaceae) showed greater inhibition zone for Streptococcus mutans $(26.0 \mathrm{~mm})$. The presented results should encourage the development of validation studies, ensuring the safe and effective use of plant species in dentistry.

Keywords: Medicinal plants; oral health; oral pathogens; in vitro; review. 


\section{INTRODUÇÃO}

A diversidade de ecossistemas do planeta, associada aos avanços dos estudos químicos e farmacológicos têm estimulado a pesquisa com espécies vegetais, contribuindo na obtenção de novos produtos farmacologicamente ativos (Gilani \& Rahman, 2005; Gurib-Fakim, 2006); demonstrando que o registro de estudos etnobotânicos e etnofarmacológicos é importante para a utilização dos recursos biológicos (Muthu et al., 2006; Agra, et al., 2007b); assumindo papel fundamental na seleção de plantas para pesquisa, quando conduzidos com metodologia apropriada (Elisabetsky, 2004).

Desse modo, levantamentos baseados no conhecimento popular de plantas usadas em afecções orais devem ser realizados, identificando espécies vegetais com potencial para uso comprovado e seguro na odontologia (Santos et al., 2009a).

Dentre os agravos a saúde bucal destaca-se a cárie, doença infecciosa comum de etiologia multifatorial, que resulta do acúmulo de microrganismos formadores da placa dentária ou biofilme bacteriano no interior e sobre pequenas lesões da superfície do esmalte do dente, provocando desmineralização; constituindo um problema de saúde pública, atingindo grande parte da população mundial com consequências na vida social dos pacientes pela função estética e digestiva; sendo comum em áreas periféricas das cidades, influenciada por fatores socioeconômicos, precariedade nas condições de saúde bucal e carente acesso aos serviços de saúde pública (Fejerskov \& Kidd, 2007; Araújo et al., 2010).

Placa dentária é um termo que designa um biofilme de diversas comunidades microbiológicas, particularmente Streptococcus orais, contidos numa matriz de polímeros de origem salivar e bacteriana. Streptococcus mutans é um dos patógenos mais relacionados ao desenvolvimento de cárie; o grupo mutans adere à superfície do dente, fermentando carboidratos e liberando ácidos que provocam a desmineralização do esmalte dentário (Nogueira et al., 2007; Babpour, et al., 2009).

A doença periodontal, afecção oral também muito comum, é uma infecção crônica associada a microrganismos anaeróbios que causam danos ao ligamento periodontal e osso alveolar. A etiologia primária se deve à presença da placa bacteriana (biofilme) que se acumula nos tecidos dentários. Essa placa produz endotoxinas (lipopolissacarídeos) e induz a formação de citocinas que são produzidas como resposta imediata do organismo a qualquer tipo de agressão, iniciando-se um processo inflamatório (Souza et al., 2006).

Bactérias do gênero Lactobacillus compreendem um grupo de organismos que tem um papel mais importante na progressão do que na instalação da cárie dental. Eles possuem capacidade acidogênica (produzir ácido) e acidúrica (sobreviver no meio ácido) além de metabolismo oxidativo e fermentativo. As espécies $L$. casei, L. acidophilus, L. plantarum e L. salivarius são homofermentativas, produzem ácido lático. Embora esses microrganismos não desempenhem papel preponderante como agente etiológico inicial da cárie, os lactobacilos parecem ser invasores secundários em algumas lesões cariosas, contribuindo para a progressão destas, devido a suas caraterísticas acidogênicas (Leites et al., 2006).

Algumas infecções orais podem ser causadas por Staphylococcus aureus, como por exemplo, queilite angular, parotidite e mucosite estafilocócica. Além disso, há evidências que sugerem que os estafilococos podem ser frequentemente isolados da cavidade oral de grupos específicos de pacientes, como crianças, idosos e alguns grupos com doença sistêmica, como os doentes terminais e pacientes com artrite reumatóide. A participação de $S$. aureus na etiologia da mucosite oral é complicada pela diversidade da flora oral e pelo transporte normal de $S$. aureus, em alguns grupos de pacientes. No entanto, as altas taxas de $S$. aureus em pacientes com sintomas da que variam de dor, ardor, eritema e edema da mucosa oral, sugerem que é necessário abordar a possibilidade deste agente desempenhar um papel em doenças da mucosa oral. Isolados de S. aureus são capazes de produzir grande variedade de exotoxinas identificadas em isolados orais (Smith et al., 2003).

A dificuldade do controle de bactérias no biofilme dental, a falta de eficácia dos agentes antimicrobianos, associado aos efeitos adversos despertam a atenção na busca de drogas mais efetivas. Desse modo, algumas plantas têm sido pesquisadas no combate a infecções orais, causadas principalmente por bactérias do biofilme (Melo et al., 2006).

Nesse sentido, o presente trabalho tem por objetivo realizar revisão dos estudos do emprego popular de espécies vegetais em odontologia; bem como dos trabalhos de avaliação da atividade antimicrobiana in vitro de extratos, frações e substâncias isolados de espécies vegetais contra patógenos orais.

\section{MÉTODOS}

Foram realizados levantamentos nas principais fontes de pesquisa científica (Biological Abstracts, Chemical Abstracts, Medline, Lilacs, Web of Science e Scielo), abrangendo o período de 1996 a 2011. 
As referências dos estudos etnofarmacológicos foram analisadas para organização das espécies vegetais por famílias, identificação das partes usadas, preparações e indicações de uso. A revisão dos estudos de atividade antimicrobiana in vitro de extratos vegetais e frações foi organizada por famílias, constando tabela de origem, parte usada, preparação, cepa de microrganismo empregada, modelo experimental e resultado, seguido da referência. As substâncias químicas isoladas de espécies vegetais foram organizadas por ordem alfabética, com identificação da classe química, espécies vegetais de origem, modelo experimental, cepa de microrganismo empregada e resultado, seguido da referência.

\section{RESULTADOS E DISCUSSÃO}

Trinta e quatro trabalhos de investigação do uso de espécies vegetais em afecções orais, realizados na Índia, Paquistão, Namíbia, Burkina Faso, Portugal, Estados Unidos, Jamaica, Costa Rica, Colômbia e Brasil (Tabela 1) foram analisados. Nesses estudos foram referidas 47 (quarenta e sete) famílias botânicas, com maior número de citações para Anacardiaceae (16), Compositae (11), Meliaceae (08), Lamiaceae (06), Solanaceae (06) e Zingiberaceae (06). Foram referidas 111 (cento e onze) espécies vegetais, sendo Anacardium occidentale L. (08), Azadirachta indica A. Juss. (05), Zingiber officinale Roscoe (05) e Punica granatum L.(04) as mais citadas.

Diversos países desenvolvidos e em desenvolvimento têm explorado sua biodiversidade natural visando a saúde bucal. Espécies vegetais são usadas na América do Norte, Central e do Sul para dor e condições ulcerativas orais; destacando Piper sp., Capsicum annuum L., Nicotiana tabacum L. e Z. officinale para odontalgia; Arnica montana L., Calendula officinalis L., Salvia officinalis L., Aloe vera L., Allium sativum L. e A. indica como antiinflamatórias (Colvard et al., 2006).

$\mathrm{Na}$ Índia, estudo com 245 (duzentos e quarenta e cinco) curandeiros indicou 35 (trinta e cinco) espécies vegetais locais, para o tratamento doenças orais; destacando Acacia nilotica var. adansonii (Guill.\&Perr.) dada indicação de atividade contra várias bactérias orais (Hebbar et al., 2004).

Em Burkina Faso, África ocidental, decocto das folhas de Carica papaya L. e Ipomoea batatas (L.) Lam. são referidas para odontalgia; e sementes de A. nilotica para o tratamento da gengivite (Tapsoba \& Deschamps, 2006). Ainda na África, forma peculiar do emprego de espécies vegetais, refere-se à higiene oral por meio de "gravetos de mascar", usados na confecção de escovas dentais, a partir da raiz de Salvadora persica L. e/ ou Azadirachta indica A. Juss.; justificando o uso por razões sociais, econômicas e religiosas (Marwat et al., 2009; Muhammad \& Lawal, 2010).

No Brasil, a maioria dos estudos do uso popular de plantas em odontologia, tem sido realizada na região nordeste. Gazzaneo et al. (2005), em inquérito realizado em Pernambuco, identificaram Protium heptaphyllum March como espécie mais referida, sendo usada para dor de dente. Em Natal, Rio Grande do Norte, Lima Júnior et al. (2005) referem o emprego de $P$. granatum, Hura crepitans L., A. occidentale e Malva parviflora L., para cicatrização, odontalgia, afta, inflamação e erupção dentária; enquanto Lima Júnior \& Dimenstein (2006) referem Lippia sidoides Cham. no tratamento de afta e abscesso dentário, $A$. occidentale como cicatrizante e $P$. granatum para gengivite.

Ainda no nordeste brasileiro, levantamentos realizados no cariri paraibano por Agra et al. indicam Zizyphus cotinifolia Reiss. na higiene oral; Tamarindus indica L., Hyptis suaveolens (L.) Poit., Blainvillea acmella (L.) Philipson e Pilocarpus jaborandi Holmes para odontalgia.

A predominância de espécies vegetais referidas pertencentes à família Anacardiaceae, com ampla distribuição em regiões tropical e subtropical, reflete sua representatividade na flora brasileira, especialmente na região nordeste (Lorenzi, 2005; Barreto, 2006).

Analisando os trabalhos realizados no Brasil, observa-se diversidade das espécies vegetais empregadas em odontologia, predominando $A$. occidentale e $P$. granatum, porém não há concordância na indicação popular; dado relevante considerando que a grande extensão territorial do país, junto às diferenças sócio-econômico-culturais da população pode refletir sobre o valor atribuído ao uso de plantas como recurso e/ou indicação terapêutica atribuída a cada espécie (Vendruscolo \& Mentz, 2006; Amaral, 2007).

A tabela 1 demonstra que a indicação do uso de plantas mais referida foi odontalgia, seguida de inflamação gengival; sendo também relatado o uso para higiene oral, erupção dentária, cicatrização pós-extração, úlceras orais, sangramento gengival e infecções bucais. O amplo emprego para odontalgia é justificado, considerando que dor é uma das mais importantes consequências da cárie, com impacto negativo na qualidade de vida (Shepherd et al., 1999; Pau et al., 2000; Pau et al., 2003); principalmente na população economicamente desfavorecida (Pau et al., 2003; Bastos et al. 2007).

Folhas, seguida de casca, caule, fruto, semente, flor e/ou raiz são os órgãos mais empregados, dependendo da espécie ou indicação de uso. Em relação ao modo de preparação do

Rev. Bras. PI. Med., Campinas, v.16, n.1, p.135-167, 2014. 
TABELA 1. Famílias e espécies vegetais referidas de uso popular em afecções da cavidade oral em estudos etnofarmacológicos mundiais, com indicação do uso, parte empregada, origem do material botânico e modo de preparação

\begin{tabular}{|c|c|c|c|c|c|c|}
\hline Família & Nome botânico & Origem & Parte usada & Preparação & Indicação & Referências \\
\hline \multirow[t]{5}{*}{ Acanthaceae } & Blepharis repens & Índia & parte jovem & mastigação & afta & Hebbar et al., 2004 \\
\hline & (Vahl.) & & & & & \\
\hline & Justicia pectoralis & Brasil & folha & decocção/ infusão & odontalgia & Borba \& Macedo, \\
\hline & var. stenophylla & & & & & 2006 \\
\hline & Leon. & & & & & \\
\hline \multirow[t]{4}{*}{ Amaranthaceae } & Alternanthera & Brasil & folha & decocção/ infusão & inflamação & Borba \& Macedo, \\
\hline & brasiliana Kuntze & & & & & 2006 \\
\hline & Gomphrena vaga & Brasil & raiz/ folha/ & infusão & odontalgia & Agra et al., 2007b \\
\hline & Mart. & & planta inteira & & & \\
\hline \multirow[t]{27}{*}{ Anacardiaceae } & Anacardium & Brasil & $\mathrm{NI}$ & infusão/ decocção/ & odontalgia/ & Lima Júnior et al., \\
\hline & occidentale L. & & & lambedor/ & cicatrização/ afta/ & 2005 \\
\hline & & & & maceração & inflamação & \\
\hline & & Brasil & casca do & decocção & inflamação/ & Albuquerque, 2006 \\
\hline & & & caule & & machucadura & \\
\hline & & Brasil & folha & decocção & cicatrização & Lima Júnior \& \\
\hline & & & & & & Dimenstein, 2006 \\
\hline & & Brasil & fruto/ folha & decocção & odontalgia/ gengivite/ & Borba \& Macedo, \\
\hline & & & & & erupção dentária & 2006 \\
\hline & & Brasil & casca/ folha & decocção & inflamação & Gomes et al., 2008 \\
\hline & & Brasil & $\mathrm{NI}$ & infusão & inflamação & Santos et al., 2009a \\
\hline & & Brasil & casca & $\mathrm{NI}$ & sangramento gengival & Oliveira et al., 2010 \\
\hline & & Brasil & entrecasca & $\mathrm{NI}$ & odontalgia/ferida/afta & Oliveira et al., 2011 \\
\hline & Astronium & Brasil & resina/ casca & $\mathrm{NI}$ & odontalgia & Agra et al., 2007b \\
\hline & fraxinifolium Schott & & do caule & & & \\
\hline & ex Spreng. & & & & & \\
\hline & Mangifera indica L. & Índia & casca & mastigação & odontalgia & Hebbar et al., 2004 \\
\hline & & Brasil & broto & $\mathrm{NI}$ & odontalgia /infecção & Oliveira et al., 2011 \\
\hline & & Índia & parte aérea & mastigação & higiene oral & Prashant et al., 2007 \\
\hline & Myracrotrum & Brasil & casca & infusão & inflamação & Gomes et al., 2008 \\
\hline & urundeuva Allemão & & & & & \\
\hline & Schinus & Brasil & $\mathrm{NI}$ & infusão & inflamação & Santos et al., 2009a \\
\hline & terebinthifolius & & & & & \\
\hline & Raddi & & & & & \\
\hline & Spondias lutea L. & Brasil & fruto & $\mathrm{NI}$ & odontalgia & Oliveira et al., 2010 \\
\hline & Spondias purpurea & Jamaica & $\mathrm{NI}$ & $\mathrm{NI}$ & infecção gengival & Mitchell \& Ahmad, \\
\hline & $\mathrm{L}$. & & & & & 2006 \\
\hline Apocynaceae & Calotropis procera & Brasil & látex & $\mathrm{NI}$ & odontalgia & Agra et al., 2007b \\
\hline & (Aiton) WT. Aiton & & & & & \\
\hline Araceae & Acorus calamus L. & Índia & rizoma & $\mathrm{NI}$ & odontalgia & Hebbar et al., 2004 \\
\hline Bignoniaceae & Tabebuia & Brasil & casca & decocção & inflamação & Borba \& Macedo, \\
\hline & heptaphylla Vell. & & & & & 2006 \\
\hline \multirow[t]{5}{*}{ Burseraceae } & Bursera & Brasil & resina & $\mathrm{NI}$ & odontalgia & Lima Júnior \& \\
\hline & leptopholeos (Mart.) & & & & & Dimenstein, 2006. \\
\hline & Engl. & & & & & \\
\hline & Protium heptaphyllum & Brasil & resina & $\mathrm{NI}$ & odontalgia & Gazzaneo et al., \\
\hline & (Aubl.) March. & & & & & 2005 \\
\hline \multirow[t]{6}{*}{ Caesalpiniaceae } & Caesalpinia coriaria & Índia & fruto & trituração & odontalgia & Hebbar et al., 2004 \\
\hline & (Jacq.) Willd. & & & & & \\
\hline & Tamarindus indica L. & Burkina Faso & folha & decocção & úlcera & Tapsoba \& \\
\hline & & & & & & Deschamps, 2006 \\
\hline & & Brasil & folha & decocção & odontalgia & Agra et al., 2007b \\
\hline & & Brasil & $\mathrm{NI}$ & $\mathrm{NI}$ & inflamação dentária & Santana et al., 2008 \\
\hline
\end{tabular}


TABELA 1. Famílias e espécies vegetais referidas de uso popular em afecções da cavidade oral em estudos etnofarmacológicos mundiais, com indicação do uso, parte empregada, origem do material botânico e modo de preparação

continuação...

\begin{tabular}{|c|c|c|c|c|c|c|}
\hline Família & Nome botânico & Origem & Parte usada & Preparação & Indicação & Referências \\
\hline Capifloraceae & Sambucus nigra L. & Brasil & flor & infusão & erupção dentária & Gomes et al., 2008 \\
\hline \multirow[t]{4}{*}{ Caricaceae } & Carica papaya L. & Índia & látex & $\mathrm{NI}$ & odontalgia & Hebbar et al., 2004 \\
\hline & & Burkina Faso & folha & infusão & odontalgia & Tapsoba \& \\
\hline & & & & & & Deschamps, 2006 \\
\hline & & Brasil & flor & decocção & inflamação & $\begin{array}{l}\text { Borba \& Macedo, } \\
2006\end{array}$ \\
\hline Chenopodiaceae & $\begin{array}{l}\text { Chenopodium } \\
\text { ambrosioides L. }\end{array}$ & Brasil & $\begin{array}{c}\text { ramo/ folha/ } \\
\text { raiz }\end{array}$ & $\begin{array}{c}\text { infusão/ decocção/ } \\
\text { maceração }\end{array}$ & $\begin{array}{c}\text { antibiótico/ } \\
\text { inflamação/ } \\
\text { cicatrização }\end{array}$ & Borba \& Macedo, 2006 \\
\hline Cistaceae & Xolantha tuberaria L. & Portugal & planta inteira & decocção & inflamação dentária & Carvalho et al., 2007 \\
\hline \multirow[t]{13}{*}{ Compositae } & $\begin{array}{c}\text { Achyrocline } \\
\text { satureioides (Lam.) }\end{array}$ & Brasil & flor & infusão & erupção dentária & Medeiros et al., 2004 \\
\hline & DC. & & & & & \\
\hline & & Brasil & parte aérea & $\mathrm{NI}$ & odontalgia & $\begin{array}{l}\text { Vendruscolo \& } \\
\text { Mentz, } 2006\end{array}$ \\
\hline & $\begin{array}{l}\text { Acmella ciliata } \\
\text { (Kunth) Cass. }\end{array}$ & Brasil & flor & $\mathrm{NI}$ & odontalgia & Oliveira et al., 2010 \\
\hline & Arnica montana $\mathrm{L}$. & E.U.A./ & $\mathrm{NI}$ & $\mathrm{NI}$ & úlcera oral/ inflamação & Colvard et al., 2006 \\
\hline & & $\begin{array}{l}\text { Costa Rica/ } \\
\text { Colômbia }\end{array}$ & & & & \\
\hline & $\begin{array}{c}\text { Bidens cynapifolia } \\
\text { HBK. }\end{array}$ & Brasil & planta inteira & $\mathrm{NI}$ & $\begin{array}{c}\text { odontalgia/ infecção/ } \\
\text { gengivite }\end{array}$ & Oliveira et al., 2011 \\
\hline & $\begin{array}{l}\text { Blainvillea acmella } \\
\text { (L.) Philipson }\end{array}$ & Brasil & flor & maceração & odontalgia & Agra et al., 2007b \\
\hline & $\begin{array}{c}\text { Matricaria } \\
\text { chamomilla L. }\end{array}$ & Brasil & folha/ ramo & decocção/ infusão & erupção dentária & $\begin{array}{l}\text { Borba \& Macedo, } \\
2006\end{array}$ \\
\hline & $\begin{array}{c}\text { Pluchea carolinensis } \\
\text { (Jacq.) G. Don }\end{array}$ & Cuba & folha & decocção & odontalgia & Beyra et al., 2004 \\
\hline & $\begin{array}{l}\text { Pluchea sagitallis } \\
\text { (Lam.) }\end{array}$ & Brasil & $\mathrm{NI}$ & $\mathrm{NI}$ & odontalgia & Ritter et al., 2002 \\
\hline & $\begin{array}{c}\text { Spilanthes acmella } \\
\text { Mart. }\end{array}$ & Brasil & folha/ flor & decocção/ infusão & odontalgia & Holetz et al., 2002 \\
\hline & $\begin{array}{c}\text { Vernonia ferruginea } \\
\text { Less. }\end{array}$ & Brasil & folha & $\mathrm{NI}$ & odontalgia & Oliveira et al., 2011 \\
\hline \multirow[t]{5}{*}{ Convolvulaceae } & Ipomoea batatas (L.) & Brasil & folha jovem & $\mathrm{NI}$ & inflamação gengival & Vendruscolo \& \\
\hline & Lam. & & & & & Mentz, 2006 \\
\hline & & Brasil & folha & decocção & odontalgia & Borba \& Macedo, 2006 \\
\hline & & Brasil & folha & uso tópico & odontalgia/infecção & Oliveira et al., 2011 \\
\hline & $\begin{array}{c}\text { Operculina } \\
\text { macrocarpa (L.) Urb. }\end{array}$ & Brasil & semente & $\mathrm{NI}$ & erupção dentária & Oliveira et al., 2010 \\
\hline Cyperaceae & $\begin{array}{c}\text { Cyperus articulatus } \\
\text { L. }\end{array}$ & Jamaica & $\mathrm{NI}$ & $\mathrm{NI}$ & odontalgia & $\begin{array}{c}\text { Mitchell \& Ahmad, } \\
2006 \\
\end{array}$ \\
\hline Ebenaceae & $\begin{array}{c}\text { Diospyros lycioides } \\
\text { Maytenus }\end{array}$ & Namíbia & parte aérea & mastigação & higiene oral & Cai et al., 2000 \\
\hline Euphorbiaceae & Hura crepitans L. & Brasil & $\mathrm{NI}$ & $\begin{array}{c}\text { infusão/ decocção/ } \\
\text { maceração }\end{array}$ & $\begin{array}{c}\text { cicatrização/ } \\
\text { odontalgia/ inflamação }\end{array}$ & $\begin{array}{l}\text { Lima Júnior et al., } \\
2005\end{array}$ \\
\hline
\end{tabular}


TABELA 1. Famílias e espécies vegetais referidas de uso popular em afecções da cavidade oral em estudos etnofarmacológicos mundiais, com indicação do uso, parte empregada, origem do material botânico e modo de preparação

continuação...

\begin{tabular}{|c|c|c|c|c|c|c|}
\hline Família & Nome botânico & Origem & Parte usada & Preparação & Indicação & Referências \\
\hline \multirow[t]{8}{*}{ Fabaceae } & Cassia ferruginea & Brasil & folha & decocção & inflamação dentária & Alves et al., 2008 \\
\hline & (Schrader) & Brasil & folha & $\mathrm{NI}$ & sangramento gengival & Vendruscolo \& \\
\hline & Erythrina falcata & Brasil & fruto & trituração & odontalgia & Mentz, 2006 \\
\hline & Benth. & & & & & Agra et al., 2007a \\
\hline & Erythrina velutina & & & & & \\
\hline & Willd. & & & & & \\
\hline & Inga sessilis (Vell.) & Brasil & casca & decocção & higiene oral & Alves et al., 2008 \\
\hline & Mart. & & & & & \\
\hline Iridaceae & $\begin{array}{c}\text { Eleutherine bulbosa } \\
\text { (Mill.) Urb. }\end{array}$ & Brasil & bulbo & infusão & dentição & Santos et al., 2009a \\
\hline Labiatae & $\begin{array}{c}\text { Cunila microcephala } \\
\text { Benth. }\end{array}$ & Brasil & caule & $\mathrm{NI}$ & odontalgia/ferida/afta & Oliveira et al., 2011 \\
\hline \multirow[t]{9}{*}{ Lamiaceae } & $\begin{array}{l}\text { Hyptis suaveolens } \\
\text { (L.) Poit. }\end{array}$ & Brasil & flor & infusão/ decocção & odontalgia & $\begin{array}{l}\text { Agra et al., 2007b, } \\
\text { Agra et al., 2007a }\end{array}$ \\
\hline & Mentha pulegium L. & Brasil & folha/ ramo & infusão/ decocção & erupção dentária & Borba \& Macedo, 2006 \\
\hline & Mentha spicata L. & Brasil & planta inteira & $\mathrm{NI}$ & odontalgia & Oliveira et al., 2011 \\
\hline & $\begin{array}{c}\text { Rhaphiodon echinus } \\
\text { (Nees e Mart.) }\end{array}$ & Brasil & $\mathrm{NI}$ & $\mathrm{NI}$ & inflamação dentária & Santana et al., 2008 \\
\hline & Rosmarinus & Brasil & folha/ flor & infusão & erupção dentária & Borba \& Macedo, 2006 \\
\hline & officinalis $\mathrm{L}$. & & & & & \\
\hline & Salvia officinalis L. & E.U.A./ & $\mathrm{NI}$ & $\mathrm{NI}$ & úlcera oral/ inflamação & Colvard et al., 2006 \\
\hline & & Costa Rica/ & & & & \\
\hline & & Colômbia & & & & \\
\hline \multirow[t]{4}{*}{ Lecythidaceae } & Cariniana & Brasil & $\mathrm{NI}$ & $\mathrm{NI}$ & afecções bucais & Souza \& Felfili, 2006 \\
\hline & estrellensis Raddi & Brasil & casca & decocção & afta & Alves et al., 2008 \\
\hline & Cariniana rubra & Brasil & entrecasca & decocção/ & inflamação & Borba \& Macedo, 2006 \\
\hline & Gardner ex. Miers & & & maceração & & \\
\hline \multirow[t]{7}{*}{ Leguminosae } & Acacia & Burkina Faso & casca & decocção & sangramento gengival & Tapsoba \& \\
\hline & macrostachya Rchb. & & & & & Deschamps, 2006 \\
\hline & ex DC. & & & & & \\
\hline & Plathymenia & Brasil & casca & maceração & odontalgia & Borba \& Macedo, 2006 \\
\hline & reticulata Benth. & & & & & \\
\hline & Stryphnodendron & Brasil & casca & infusão & inflamação & Gomes et al., 2008 \\
\hline & barbatimao Mart. & & & & & \\
\hline \multirow[t]{9}{*}{ Lilaceae } & Aloe vera $\mathrm{L}$. & E.U.A./ & $\mathrm{NI}$ & $\mathrm{NI}$ & úlcera oral/ inflamação & Colvard et al., 2006 \\
\hline & & Costa Rica/ & & & & \\
\hline & & Colômbia & & & & \\
\hline & & Brasil & folha & maceração & úlcera oral/ & Borba \& Macedo, 2006 \\
\hline & & & & & inflamação & \\
\hline & Allium sativum $\mathrm{L}$. & E.U.A./ & $\mathrm{NI}$ & $\mathrm{NI}$ & úlcera oral/ inflamação & Colvard et al., 2006 \\
\hline & & Costa Rica/ & & & & \\
\hline & & Colômbia & & & & \\
\hline & & Índia & bulbo & mastigação & odontalgia & Hebbar et al., 2004 \\
\hline \multirow[t]{4}{*}{ Lythraceae } & Lafoensia pacari & Brasil & entrecasca & maceração/ & estomatite/ gengivite & Borba \& Macedo, 2006 \\
\hline & St. Hil & & & infusão & & \\
\hline & & Brasil & folha/ & $\mathrm{NI}$ & odontalgia & Oliveira et al., 2011 \\
\hline & & & entrecasca & & & \\
\hline
\end{tabular}


TABELA 1. Famílias e espécies vegetais referidas de uso popular em afecções da cavidade oral em estudos etnofarmacológicos mundiais, com indicação do uso, parte empregada, origem do material botânico e modo de preparação

continuação..

\begin{tabular}{|c|c|c|c|c|c|c|}
\hline Família & Nome botânico & Origem & Parte usada & Preparação & Indicação & Referências \\
\hline \multirow[t]{7}{*}{ Malpighiaceae } & Camarea ericoides & Brasil & folha/ ramo & decocção/ & odontalgia/ extração & Borba \& Macedo, 2006 \\
\hline & A.St.Hil. & & & maceração & dentária/ infecção/ & \\
\hline & & & & & machucadura & \\
\hline & Byrsonima & Brasil & casca & $\mathrm{NI}$ & sangramento gengival & Oliveira et al., 2010 \\
\hline & correaefolia A. Juss. & & & & & \\
\hline & Byrsonima variabilis & Brasil & casca & $\mathrm{NI}$ & sangramento gengival & Oliveira et al., 2010 \\
\hline & A. Juss. & & & & & \\
\hline \multirow[t]{11}{*}{ Malvaceae } & Abutilon indicum $\mathrm{L}$. & Índia & folha & $\mathrm{NI}$ & problema dentário & Muthu et al., 2006 \\
\hline & Gossypium sp. & Brasil & folha/ & uso tópico & infecção/odontalgia & Oliveira et al., 2011 \\
\hline & & & semente & & & \\
\hline & Malvaviscus & Brasil & $\mathrm{NI}$ & decocção/ & odontalgia/ inflamação & Lima Júnior et al., \\
\hline & arboreus Dill. ex & & & lambedor/ & & 2005 \\
\hline & Cav. & & & maceração & & \\
\hline & Malva parviflora L. & Brasil & $\mathrm{NI}$ & infusão/ decocção/ & afta/ inflamação & Lima Júnior et al., \\
\hline & & & & lambedor/ & & 2005 \\
\hline & & & & maceração & & \\
\hline & & Brasil & folha & decocção/infusão & anti-inflamatório & Barros et al., 2007 \\
\hline & Malva sylvestris L. & Brasil & $\mathrm{NI}$ & $\mathrm{NI}$ & inflamação gengival & Ritter et al., 2002 \\
\hline \multirow[t]{2}{*}{ Melastomatacea } & $\mathrm{NI}$ & Brasil & semente/ & $\mathrm{NI}$ & odontalgia & Gazzaneo et al., \\
\hline & & & folha & & & 2005 \\
\hline \multirow[t]{14}{*}{ Meliaceae } & Khaya senegalensis & Burkina Faso & casca & decocção & sangramento gengival & Tapsoba \& \\
\hline & (Desr.) A. Juss. & & & & & Deschamps, 2006 \\
\hline & Azadirachta indica & Índia & casca & trituração & odontalgia & Hebbar et al., 2004 \\
\hline & A. Juss. & E.U.A./ & $\mathrm{NI}$ & $\mathrm{NI}$ & úlcera oral/ inflamação & Colvard et al., 2006 \\
\hline & & Costa Rica/ & & & & \\
\hline & & Colômbia & & & & \\
\hline & & Jamaica & $\mathrm{NI}$ & $\mathrm{NI}$ & odontalgia & Mitchell \& Ahmad, \\
\hline & & & & & & 2006 \\
\hline & & Burkina Faso & parte aérea & mastigação & higiene oral & Tapsoba \& \\
\hline & & & & & & Deschamps, 2006 \\
\hline & & Índia & parte aérea & mastigação & higiene oral & Prashant et al., 2007 \\
\hline & Cedrela fissilis Vell. & Brasil & casca & infusão & afta & Alves et al., 2008 \\
\hline & Cedrela odorata L. & Brasil & entrecasca & decocção & inflamação & Borba \& Macedo, \\
\hline & & & & & & 2006 \\
\hline \multirow[t]{7}{*}{ Mimosaceae } & Acacia nilotica & Burkina Faso & fruto/ casca/ & maceração & odontalgia/ gengivite/ & Tapsoba \& \\
\hline & var. adansonii & & folha & & úlcera & Deschamps, 2006 \\
\hline & (Guill.\&Perr.) & & & & & \\
\hline & Inga vera Willd. & Brasil & casca do & $\mathrm{NI}$ & afta & Rodrigues \& \\
\hline & & & caule & & & Carvalho, 2001 \\
\hline & Mimosa tenuiflora & Brasil & casca do & infusão & odontalgia/ inflamação & Albuquerque, 2006 \\
\hline & (Willd.) Poir. & & caule & & & \\
\hline \multirow[t]{4}{*}{ Moraceae } & Dortsenia asaroides & Brasil & raiz & decocção & odontalgia/ & Borba \& Macedo, 2006 \\
\hline & Gardn. & & & & inflamação & \\
\hline & Dorstenia & Brasil & rizoma & $\mathrm{NI}$ & inflamação/ odontalgia & Rodrigues \& \\
\hline & brasiliensis Lam. & & & & & Carvalho, 2001 \\
\hline
\end{tabular}


TABELA 1. Famílias e espécies vegetais referidas de uso popular em afecções da cavidade oral em estudos etnofarmacológicos mundiais, com indicação do uso, parte empregada, origem do material botânico e modo de preparação

continuação...

\begin{tabular}{|c|c|c|c|c|c|c|}
\hline Família & Nome botânico & Origem & Parte usada & Preparação & Indicação & Referências \\
\hline \multirow[t]{9}{*}{ Myrtaceae } & Eucaliptus globulus & Brasil & folha & infusão/ decocção & ferida na boca & Borba \& Macedo, 2006 \\
\hline & Labil. & & & & & \\
\hline & Myrcia salicifolia DC. & Brasil & $\mathrm{NI}$ & $\mathrm{NI}$ & afta & Santos et al., 2009a \\
\hline & Psidium guajava L. & Índia & folha jovem & mastigação & odontalgia & Hebbar et al., 2004 \\
\hline & & Brasil & folha/ casca/ & infusão/ decocção/ & afta/ erupção & Borba \& Macedo, 2006 \\
\hline & & & entrecasca & in natura & dentária/ & \\
\hline & & & & & odontalgia/ limpeza & \\
\hline & Syzygium & Brasil & $\mathrm{NI}$ & $\mathrm{NI}$ & halitose/ odontalgia & Santos et al., 2009a \\
\hline & aromaticum L. & & & & & \\
\hline \multirow[t]{5}{*}{ Olacaceae } & Ximenia americana & Brasil & $\mathrm{NI}$ & $\mathrm{NI}$ & cicatrização & Lima Júnior \& \\
\hline & L. & & & & & Dimenstein, 2006. \\
\hline & & Burkina Faso & folha/ raiz/ & decocção & odontalgia & Tapsoba \& \\
\hline & & & casca & & & Deschamps, 2006 \\
\hline & & Brasil & casca & infusão & inflamação & Gomes et al., 2008 \\
\hline \multirow[t]{4}{*}{ Oxalidaceae } & Oxalis acetosella & Brasil & folha & maceração & afta/odontalgia & Oliveira et al., 2011 \\
\hline & Linnaeus & & & & & \\
\hline & Oxalis hirsutissima & Brasil & caule/ folha & $\mathrm{NI}$ & afecções do aparelho & Rodrigues \& \\
\hline & Mart. et. Zucc. & & & & bucal & Carvalho, 2001 \\
\hline Phytolacaceae & Petiveria alliacea L. & Brasil & $\mathrm{NI}$ & $\mathrm{NI}$ & odontalgia & Ritter et al., 2002 \\
\hline \multirow[t]{7}{*}{ Piperaceae } & Ottonia & Brasil & folha & decocção & odontalgia/ gengivite & Borba \& Macedo, 2006 \\
\hline & corcovadensis Miq. & & & & & \\
\hline & Piper aduncum L. & Jamaica & $\mathrm{NI}$ & $\mathrm{NI}$ & odontalgia & Mitchell \& Ahmad, 2006 \\
\hline & Piper betle L. & Jamaica & $\mathrm{NI}$ & $\mathrm{NI}$ & odontalgia & Mitchell \& Ahmad, 2006 \\
\hline & Piper sp. & E.U.A./ & $\mathrm{NI}$ & $\mathrm{NI}$ & odontalgia/ inflamação & Colvard et al., 2006 \\
\hline & & Costa Rica/ & & & & \\
\hline & & Colômbia & & & & \\
\hline \multirow[t]{4}{*}{ Plantaginaceae } & Plantago australis L. & Brasil & folha/ flor/ raiz & decocção/infusão & odontalgia & Barros et al., 2007 \\
\hline & Plantago major L. & & inflamação/ & folha/ semente & $\mathrm{NI}$ & Holetz et al., 2002 \\
\hline & & Brasil & folha & infusão & afta/ inflamação & Borba \& Macedo, 2006 \\
\hline & & & & & gengival & \\
\hline \multirow[t]{2}{*}{ Plumbaginaceae } & Plumbago scandens & Brasil & Raiz & extração & odontalgia & Morais et al., 2005 \\
\hline & $\mathrm{L}$. & & & & & \\
\hline \multirow[t]{9}{*}{ Punicaceae } & Punica granatum L. & Brasil & $\mathrm{NI}$ & infusão/ decocção/ & odontalgia/ & Lima Júnior et al., \\
\hline & & & & lambedor/ & cicatrização/ afta/ & 2005 \\
\hline & & & & maceração & inflamação/ erupção & \\
\hline & & & & & dentária & \\
\hline & & Brasil & $\mathrm{NI}$ & $\mathrm{NI}$ & gengivite/ cicatrização & Lima Júnior \& \\
\hline & & & & & & Dimenstein, 2006. \\
\hline & & Brasil & fruto & maceração & erupção dentária/ & Borba \& Macedo, 2006 \\
\hline & & & & & afta & \\
\hline & & Brasil & $\mathrm{NI}$ & $\mathrm{NI}$ & infecção bucal & Santos et al., 2009a \\
\hline \multirow[t]{8}{*}{ Rhamnaceae } & Zizyphus cotinifolia & Brasil & casca do & trituração & tratamento dentário & Agra et al., 2007a,b \\
\hline & Reiss. & & caule & & & \\
\hline & Zizyphus joazeiro & Brasil & $\mathrm{NI}$ & $\mathrm{NI}$ & prevenção & Lima Júnior \& \\
\hline & Mart. & & & & & Dimenstein, 2006. \\
\hline & & Brasil & Raiz & trituração & tratamento dentário & Agra et al., 2007a,b, \\
\hline & & Brasil & $\mathrm{NI}$ & $\mathrm{NI}$ & sangramento gengival & Santos et al., 2009a \\
\hline & Zizyphus mauritiana & Paquistão & fruto/ folha & maceração & abscesso & Marwat et al., 2009 \\
\hline & Lam. & & & & & \\
\hline
\end{tabular}


TABELA 1. Famílias e espécies vegetais referidas de uso popular em afecções da cavidade oral em estudos etnofarmacológicos mundiais, com indicação do uso, parte empregada, origem do material botânico e modo de preparação

\begin{tabular}{|c|c|c|c|c|c|c|}
\hline Família & Nome botânico & Origem & Parte usada & Preparação & Indicação & Referências \\
\hline \multirow[t]{6}{*}{ Rutaceae } & Citrus sinensis & Brasil & raiz & $\mathrm{NI}$ & odontalgia & Oliveira et al., 2010 \\
\hline & Osbeck & & & & & \\
\hline & Pilocarpus sp. & Brasil & folha/ raiz & $\mathrm{NI}$ & odontalgia & Gazzaneo et al., \\
\hline & & & & & & 2005 \\
\hline & Pilocarpus jaborandi & Brasil & casca do & decocção & odontalgia & Agra et al., 2007b \\
\hline & Holmes & & caule & & & \\
\hline \multirow[t]{3}{*}{ Salvadoraceae } & Azima tetracantha & Índia & folha & maceração & odontalgia & Hebbar et al., 2004 \\
\hline & Lam. & & & & & \\
\hline & Salvadora persica L. & Paquistão & raiz & in natura & limpeza & Marwat et al., 2009 \\
\hline \multirow[t]{9}{*}{ Solanaceae } & Solanum surattense & Índia & fruto & trituração & odontalgia/ gengivite & Hebbar et al., 2004 \\
\hline & Burm. & & & & & \\
\hline & Capsicum sp. & Brasil & fruto & maceração & odontalgia/ fístula & Borba \& Macedo, 2006 \\
\hline & Capsicum annuum & E.U.A./ & $\mathrm{NI}$ & $\mathrm{NI}$ & odontalgia & Colvard et al., 2006 \\
\hline & $\mathrm{L}$. & Costa Rica/ & & & & \\
\hline & & Colômbia & & & & \\
\hline & Nicotiana tabacum & Jamaica & $\mathrm{NI}$ & $\mathrm{NI}$ & odontalgia & Mitchell \& Ahmad, 2006 \\
\hline & L. & Burkina Faso & folha & trituração & odontalgia/ & Tapsoba \& Deschamps, \\
\hline & & & & & gengivite & 2006 \\
\hline \multirow[t]{3}{*}{ Umbelliferae } & Foeniculum vulgare & Brasil & fruto & decocção & erupção dentária & Gomes et al., 2008 \\
\hline & Mill. & Brasil & fruto & decocção & erupção dentária & Gomes et al., 2008 \\
\hline & Pimpinella anisum $\mathrm{L}$. & & & & & \\
\hline \multirow[t]{6}{*}{ Verbenaceae } & Lippia Iupulina & Brasil & folha/ flor & $\mathrm{NI}$ & infecção bucal & Rodrigues \& \\
\hline & Cham. & & & & & Carvalho, 2001 \\
\hline & & & $\mathrm{NI}$ & $\mathrm{NI}$ & afta/ abscesso dentário & Lima Júnior \& \\
\hline & & & & & & Dimenstein, 2006. \\
\hline & Stachytarpheta & Brasil & folha & decocção & odontalgia & Medeiros et al., 2004 \\
\hline & cayennensis Vahl & & & & & \\
\hline \multirow[t]{3}{*}{ Violaceae } & Hybanthus & Brasil & flor & $\mathrm{NI}$ & erupção dentária & Oliveira et al., 2010 \\
\hline & oppositifolius (L.) & & & & & \\
\hline & Taub. & & & & & \\
\hline \multirow[t]{11}{*}{ Zingiberaceae } & Curcuma zedoaria & Brasil & raiz & maceração/ & afta/ limpeza & Borba \& Macedo, \\
\hline & Roscoe & & & infusão/ & & 2006 \\
\hline & Zingiber officinale & Brasil & rizoma & mastigação & odontalgia & Milliken e Albert, \\
\hline & Roscoe & & & & & 1996 \\
\hline & & Brasil & folha/raiz & maceração/ & erupção dentária & Borba \& Macedo, 2006 \\
\hline & & & & infusão/ & & \\
\hline & & Jamaica & $\mathrm{NI}$ & $\mathrm{NI}$ & odontalgia & Mitchell \& Ahmad, 2006 \\
\hline & & E.U.A./ & $\mathrm{NI}$ & $\mathrm{NI}$ & odontalgia/ inflamação & Colvard et al., 2006 \\
\hline & & Costa Rica/ & & & & \\
\hline & & Colômbia & & & & \\
\hline & & Brasil & folha/ raiz & $\mathrm{NI}$ & odontalgia & Oliveira et al., 2011 \\
\hline
\end{tabular}

NI: Não informado

material, há predominância da decocção, seguida de infusão e maceração (tabela 1).

O predomínio do uso popular da decocção das folhas em afecções orais é compatível com diversos estudos etnofarmacológicos em outras áreas da saúde humana. Para Gonçalves \& Martins (1998), a maior concentração dos princípios ativos está nas folhas, justificando a frequência do uso desse órgão nas preparações. Segundo Castelluci et al. (2000), a predominância do uso das folhas é justificada pela facilidade de colheita e disponibilidade desse órgão durante todas as épocas do ano, na maioria dos biomas.

A predominância da decocção pode refletir o desconhecimento do modo ideal de preparo, considerando os riscos de perdas e/ou alterações pelo aquecimento (Pascarelli et al., 2006).

Embora reconhecendo a contribuição da etnofarmacologia no desenvolvimento de um fitoterápico, não é recomendável o pensamento 
comum de que o uso popular e tradicional é suficiente para validar espécies vegetais como medicamentos (Elisabetsky, 2004; Lapa et al., 2004). A necessidade de validação de espécies vegetais de uso popular e o reconhecimento de que o controle mecânico-químico do biofilme constitui o principal método preventivo contra cárie e doença periodontal, devem impulsionar a busca por produtos naturais com ação antimicrobiana com desenvolvimento de ensaios in vitro e in vivo, utilizando extratos de plantas, especialmente dado o surgimento de cepas bacterianas resistentes (Carvalho et al., 2009).

A revisão dos trabalhos de atividade antimicrobiana in vitro de extratos vegetais em patógenos orais (tabela 2) indica 66 (sessenta e seis) espécies vegetais, distribuídas em 38 (trinta e oito) famílias, destacando-se Anacardiaceae, seguida de Compositae, Lamiaceae e Myrtaceae. Considerando que Anacardiaceae foi a família mais representativa nos estudos etnofarmacológicos em odontologia, justifica-se maior número de estudos de atividade antimicrobiana com espécies dessa família, sendo $A$. occidentale, a espécie mais estudada.

Allium sativum L. (Liliaceae) apresentou valores de Concentração Inibitória Mínima (CIM) mais expressivos para S. mutans. Terminalia chebula Retz (Combretaceae) apresentou halo de inibição mais significativo $(32,97 \mathrm{~mm})$ contra Staphylococcus aureus (tabela 2), microrganismo frequente em infecções orais. Anogeissus leiocarpus (DC.) Guill. \& Perr. (Combretaceae) demonstrou atividade mais expressiva contra Streptococcus mutans, principal patógeno da cárie, com halo de inibição de $29,5 \mathrm{~mm}$.

A fração n-hexânica de raízes de Polygonum cuspidatum Sieb. \& Zucc. (Polygonaceae) apresentou maior halo de inibição $(16,6 \mathrm{~mm})$ contra Prevotella intermedia; enquanto o extrato aquoso dos frutos de Allium sativum apresentou valor de CIM mais expressivo para $P$. intermedia e Porphyromonas gingivalis, microrganismos envolvidos na doença periodontal.

Quanto ao método de preparação do material para avaliação da atividade antimicrobiana, a revisão demonstra trabalhos realizados com a mesma espécie vegetal submetida a diferentes preparações, predominando ensaios realizados com extratos etanólicos e/ou aquosos (tabela 2); sugerindo-se, o desenvolvimento de estudos com extratos brutos e frações, seguindo ordem de polaridade crescente dos solventes empregados para screening fitoquímico (Yunes \& Calixto, 2001; Simões et al., 2004).

Diversas espécies vegetais têm sido alvo de investigação da atividade microbiológica in vitro em patógenos orais demonstrando potencial antimicrobiano. Extrato etanólico das folhas de Psidium guajava L. inibiu o crescimento de $S$. aureus, Streptococcus mitis, Streptococcus oralis, Streptococcus mutans e Lactobacillus casei (Santos et al., 2007; Menezes et al., 2004; Prabu et al., 2006). Extrato metanólico de flores de Syzygium aromaticum L. demonstrou atividade contra $S$. mutans, Actinomyces viscosus, $P$. gingivalis e $P$. intermedia (Cai \& Wu, 1996). Extrato aquoso dos frutos de $S$. aromaticum L. também apresentou atividade contra Streptococcus sp. e L. casei (Nogueira et al., 2007).

Extrato hidroalcoólico da casca do caule de Anacardium occidentale L. demonstrou atividade contra S. mitis, S. mutans e S. sanguis (Melo et al., 2006); atividade comprovada por Araújo et al. (2009) com expressivos valores de Concentração Bactericida Mínima (CBM). Entretanto, Santos et al. (2007) com extrato etanólico da casca do caule dessa espécie não constataram atividade contra várias bactérias, inclusive Streptococcus sp.

Punica granatum, referida em estudos de etnofarmacologia (Santos et al., 2009a; Borba \& Macedo, 2006; Lima Júnior et al., 2005; Lima Júnior \& Dimenstein, 2006), em avaliação com extrato hidroalcoólico dos frutos, apresentou atividade contra S. mitis, S. mutans, S. sanguis, S. sobrinus e $L$. casei; comprovando que o material interfere no mecanismo de aderência na superfície dentária (Pereira et al., 2006).

Albuquerque et al. (2008), em estudo com extrato metanólico das folhas de Lippia sidoides Cham. comprovaram atividade contra S. mitis, $S$. mutans, S. sanguinis e S. sobrinus. Girão et al. (2003) já haviam comprovado a eficácia do óleo essencial extraído dessa planta, em ensaio in vivo realizado em cachorros com gengivite.

Considerando a atuação dos óleos essenciais como agentes antimicrobianos, diversos estudos têm sido realizados com espécies vegetais apresentando tais constituintes. Nesse sentido, óleos essenciais obtidos de Lippia sidoides Cham. (Botelho et al., 2007; Albuquerque et al., 2008), Lippia alba (Mill.) N.E. Brown, Mentha pulegium L., Mentha piperita L. (Nogueira et al., 2007) e Casearia sylvestris Sw. (Nogueira et al., 2007; Tavares et al., 2009) demonstraram atividade significativa contra patógenos orais, em especial S. mutans e L. casei.

A tabela 2 apresenta diferentes estudos realizados com mesma espécie vegetal, constatandose resultados distintos da avaliação da atividade antimicrobiana; comprovando que a atividade biológica pode estar relacionada ao local e período de coleta, idade e parte do vegetal empregada, preparação do material, cepa testada e/ou modelo de ensaio. Assim, justificam-se os resultados obtidos com A. occidentale (Melo et al., 2006; Santos et al.,

Rev. Bras. PI. Med., Campinas, v.16, n.1, p.135-167, 2014. 
TABELA 2. Extratos vegetais e frações com estudos de avaliação da atividade antimicrobiana in vitro sobre patógenos orais, com indicação da origem do material vegetal, preparação, método e microrganismo testado

\begin{tabular}{|c|c|c|c|c|c|c|c|}
\hline Família & Nome botânico & Origem & $\begin{array}{l}\text { Parte } \\
\text { usada }\end{array}$ & Preparação & Método & Microrganismo/ Resultado & Referências \\
\hline \multirow[t]{8}{*}{ Anacardiaceae } & $\begin{array}{c}\text { Anacardium } \\
\text { occidentale L. }\end{array}$ & Brasil & $\begin{array}{c}\text { casca do } \\
\text { caule }\end{array}$ & $\mathrm{EtOH}-\mathrm{H}_{2} \mathrm{O}$ & $\begin{array}{l}\text { Difusão em } \\
\text { ágar }\end{array}$ & $\begin{array}{l}\text { Halo de inibição }(\mathrm{mm}) \\
\text { S. mutans: } 11,0 \\
\text { S. mitis: } 14,0 \\
\text { S. sanguis: } 14,0\end{array}$ & $\begin{array}{l}\text { Melo et al., } \\
2006\end{array}$ \\
\hline & & Brasil & $\begin{array}{l}\text { casca do } \\
\text { caule }\end{array}$ & $\mathrm{EtOH}$ & $\begin{array}{l}\text { Diluição em } \\
\text { meio líquido }\end{array}$ & $\begin{array}{l}\text { CBM }(\mathrm{mg} / \mathrm{mL} \text { ) } \\
\text { S. mutans (ATCC 25175): 0,125 } \\
\text { S. mitis (ATCC 9811): 0,125 } \\
\text { S. sanguis (ATCC 10557): 0,25 } \\
\text { S. sobrinus (ATCC 27609): 0,125 } \\
\text { L. casei (ATCC 7469): 0,25 }\end{array}$ & $\begin{array}{c}\text { Araújo et al., } \\
2009\end{array}$ \\
\hline & & Brasil & $\begin{array}{l}\text { casca do } \\
\text { caule }\end{array}$ & $\mathrm{EtOH}$ & $\begin{array}{l}\text { Difusão em } \\
\text { ágar }\end{array}$ & $\begin{array}{c}\text { Halo de inibição (mm) } \\
\text { S. aureus: NA } \\
\text { E. faecalis: NA } \\
\text { Streptococcus sp.: NA } \\
\text { B. subtilis: NA } \\
\text { K. pneumoniae: NA }\end{array}$ & $\begin{array}{c}\text { Santos et al., } \\
2007\end{array}$ \\
\hline & Mangifera indica L. & Índia & $\begin{array}{l}\text { parte } \\
\text { aérea }\end{array}$ & $\mathrm{H}_{2} \mathrm{O}$ & $\begin{array}{l}\text { Difusão em } \\
\text { ágar }\end{array}$ & $\begin{array}{l}\text { Halo de inibição (mm) } \\
\text { S. mutans (MTCC 890): 1,5 } \\
\text { S. salivaris (ATCC 9222): 1,1 } \\
\text { S. mitis (MTCC 2695): 2,9 } \\
\text { S. sanguis (ATCC 10556): 1,0 }\end{array}$ & $\begin{array}{l}\text { Prashant et } \\
\text { al., } 2007\end{array}$ \\
\hline & $\begin{array}{l}\text { Myracrodruon } \\
\text { urundeuva All. }\end{array}$ & Brasil & $\begin{array}{l}\text { casca do } \\
\text { caule }\end{array}$ & $\mathrm{EtOH}-\mathrm{H}_{2} \mathrm{O}$ & $\begin{array}{l}\text { Difusão em } \\
\text { meio sólido }\end{array}$ & $\begin{array}{l}\text { CIM }(\mathrm{mg} / \mathrm{mL}) \\
\text { S. mutans: } 0,125 \\
\text { S. mitis: } 0,25 \\
\text { S. sanguis: } 0,125 \\
\text { S. sobrinus: } 0,25 \\
\text { L. casei: } 0,312\end{array}$ & $\begin{array}{l}\text { Alves et al., } \\
2009\end{array}$ \\
\hline & Rhus coriaria L. & $\mathrm{NI}$ & $\mathrm{NI}$ & $\mathrm{EtOH}$ & $\begin{array}{l}\text { Diluição em } \\
\text { caldo }\end{array}$ & $\begin{array}{c}\text { CIM }(\mathrm{mg} / \mathrm{mL}) \\
\text { S. mutans (ATCC 127607): 0,25 } \\
\text { S. sanguis (PTCC 1449): 0,25 }\end{array}$ & $\begin{array}{l}\text { Babpour et } \\
\text { al., } 2009\end{array}$ \\
\hline & $\begin{array}{l}\text { Schinus } \\
\text { terebinthifolius } \\
\text { Raddi }\end{array}$ & Brasil & $\begin{array}{l}\text { casca do } \\
\text { caule }\end{array}$ & $\mathrm{EtOH}$ & $\begin{array}{l}\text { Difusão em } \\
\text { ágar }\end{array}$ & $\begin{array}{l}\text { Halo de inibição }(\mathrm{mm}) \\
\text { S. mutans (ATCC 2575): 7,0 }\end{array}$ & $\begin{array}{c}\text { Soares et al., } \\
2007\end{array}$ \\
\hline & & Brasil & $\begin{array}{l}\text { casca do } \\
\text { caule }\end{array}$ & $\mathrm{EtOH}$ & Microdiluição & $\begin{array}{c}\text { CIM }(\mathrm{mg} / \mathrm{mL}) \\
\text { S. mutans (ATCC 25175): 3,125 } \\
\text { L. casei (ATCC 7469): 1,562 }\end{array}$ & $\begin{array}{l}\text { Freires et al., } \\
2010\end{array}$ \\
\hline Anacardiaceae & $\begin{array}{l}\text { Thyrsodium } \\
\text { spruceanum } \\
\text { Benth. }\end{array}$ & Brasil & folha & $\begin{array}{c}\mathrm{CHCl}_{3} \\
\mathrm{CH}_{3} \mathrm{OH} \\
\mathrm{H}_{2} \mathrm{O}\end{array}$ & $\begin{array}{l}\text { Difusão em } \\
\text { ágar }\end{array}$ & $\begin{array}{l}\text { Halo de inibição }(\mathrm{mm} \text { ) } \\
\text { S. oralis (ATCC 10557): 8,0 } \\
\text { S. sanguis (ATCC 15300): 9,0 } \\
\text { Halo de inibição (mm) } \\
\text { S. oralis (ATCC 10557): 13,0 } \\
\text { S. sanguis (ATCC 15300): 14,0 } \\
\text { Halo de inibição (mm) } \\
\text { S. oralis (ATCC 10557): 16,0 } \\
\text { S. sanguis (ATCC 15300): 14,0 }\end{array}$ & $\begin{array}{c}\text { Carneiro et } \\
\text { al., } 2008\end{array}$ \\
\hline Annonaceae & $\begin{array}{c}\text { Annona } \\
\text { senegalensis Pers. }\end{array}$ & $\begin{array}{l}\text { África do } \\
\text { Sul }\end{array}$ & casca & EtOH & $\begin{array}{c}\text { Difusão } \\
\text { em ágar e } \\
\text { microdiluição }\end{array}$ & $\begin{array}{c}\text { Halo de inibição }(\mathrm{mm}) \\
\text { A. naeslundii: } 4,5 \\
\text { A. israelii: } 5,0 \\
\text { S. mutans: } 3,0 \\
\text { P. gingivalis: } 6,5 \\
\text { P. intermedia: } 2,5 \text { CIM (mg/mL) } \\
\text { A. naes/undii (ATCC 19039): 1,6 } \\
\text { A. israelii (ATCC 10049): 3,1 } \\
\text { S. mutans (ATCC 25175): 12,5 } \\
\text { P. gingivalis (ATCC } 33277 \text { ): } 1,6\end{array}$ & $\begin{array}{c}\text { More et al., } \\
2008\end{array}$ \\
\hline
\end{tabular}


TABELA 2. Extratos vegetais e frações com estudos de avaliação da atividade antimicrobiana in vitro sobre patógenos orais, com indicação da origem do material vegetal, preparação, método e microrganismo testado

\begin{tabular}{|c|c|c|c|c|c|c|c|}
\hline \multirow[t]{7}{*}{ Avicenniaceae } & \multirow{7}{*}{$\begin{array}{c}\text { Avicennia alba } \\
\text { Blume }\end{array}$} & \multirow[t]{7}{*}{ Índia } & \multirow[t]{7}{*}{$\mathrm{NI}$} & \multirow[t]{4}{*}{$\mathrm{CHCl}_{3}$} & Difusão em & \multirow{4}{*}{$\begin{array}{l}\text { Halo de inibição (mm) } \\
\text { L. acidophilus (MTCC 447): 12,0 } \\
\text { S. mitis (MTCC 2696): NA } \\
\text { S. mutans (MTCC 890): 19,0 }\end{array}$} & \multirow{7}{*}{$\begin{array}{l}\text { Vadlapudi \& } \\
\text { Naidu, } 2009\end{array}$} \\
\hline & & & & & ágar & & \\
\hline & & & & & & & \\
\hline & & & & & & & \\
\hline & & & & \multirow[t]{3}{*}{$\mathrm{MeOH}$} & & Halo de inibição $(\mathrm{mm})$ & \\
\hline & & & & & & L. acidophilus (MTCC 447): 14,0 & \\
\hline & & & & & & S. mutans (MTCC 890): 27,0 & \\
\hline \multirow[t]{25}{*}{ Compositae } & \multirow[t]{12}{*}{ Arctium lappa L. } & Brasil & folha & $\mathrm{Hex}$ & Difusão em & Halo de inibição (mm) & Pereira et al., \\
\hline & & & & & ágar & E. faecalis (ATCC 29210): 1,4 & 2005 \\
\hline & & & & & & S. aureus (ATCC 6538): 1,4 & \\
\hline & & & & & & P. aeruginosa (ATCC 27853): 1,2 & \\
\hline & & & & & & B. subtilis (ATCC 6633): 1,2 & \\
\hline & & $\mathrm{NI}$ & raiz & $\mathrm{EtOH}$ & Difusão em & Halo de inibição (mm) & Santos et al., \\
\hline & & & & & ágar & S. aureus: NA & 2007 \\
\hline & & & & & & E. faecalis: NA & \\
\hline & & & & & & Streptococcus sp.: NA & \\
\hline & & & & & & B. subtilis: NA & \\
\hline & & & & & & E. coli: NA & \\
\hline & & & & & & K. pneumoniae: NA & \\
\hline & \multirow[t]{13}{*}{ Arnica montana L. } & Brasil & flor & $\mathrm{EtOH}$ & Difusão em & Halo de inibição $(\mathrm{mm})$ & Koo et al., \\
\hline & & & & & ágar & S. sanguis (ATCC 10556): NA & 2000 \\
\hline & & & & & & S. mutans (Ingbritt 1600): NA & \\
\hline & & & & & & A. naeslundii (ATCC 12104): 0,33 & \\
\hline & & & & & & A. naeslundii (W 1053): 0,67 & \\
\hline & & & & & & A. viscosus (OMZ 105): NA & \\
\hline & & & & & & P. gingivalis IC: 0,48 & \\
\hline & & $\mathrm{NI}$ & flor & $\mathrm{MeOH}$ & Microdiluição & $\mathrm{CIM}(\mathrm{mg} / \mathrm{mL})$ & lauk et al., \\
\hline & & & & & & P. gingivalis 1 e 4: 0,9 & 2002 \\
\hline & & & & & & P. gingivalis 2: 1,9 & \\
\hline & & & & & & P. gingivalis $3: 1,4$ & \\
\hline & & & & & & P. gingivalis 5: 1,2 & \\
\hline & & & & & & F. nucleatum: 16,38 & \\
\hline
\end{tabular}


TABELA 2. Extratos vegetais e frações com estudos de avaliação da atividade antimicrobiana in vitro sobre patógenos orais, com indicação da origem do material vegetal, preparação, método e microrganismo testado

continuação..

\begin{tabular}{|c|c|c|c|c|c|c|c|}
\hline Família & Nome botânico & Origem & $\begin{array}{l}\text { Parte } \\
\text { usada }\end{array}$ & Preparação & Método & Microrganismo/ Resultado & Referências \\
\hline & $\begin{array}{c}\text { Baccharis } \\
\text { dracunculifolia DC. }\end{array}$ & Brasil & $\mathrm{NI}$ & $\mathrm{H}_{2} \mathrm{O}$ & $\begin{array}{l}\text { Difusão em } \\
\text { ágar }\end{array}$ & $\begin{array}{l}\text { Halo de inibição (mm) } \\
\text { S. mutans (ATCC 2575): 7,3 } \\
\text { S. sobrinus (ATCC 27607): 10,4 } \\
\text { S. sanguis (ATCC 10557): 12,5 } \\
\text { L. casei (ATCC 4646): } 8,3\end{array}$ & $\begin{array}{c}\text { Ferronatto et } \\
\text { al., } 2007\end{array}$ \\
\hline Compositae & $\begin{array}{l}\text { Calendula } \\
\text { officinalis } \mathrm{L} \text {. }\end{array}$ & $\mathrm{NI}$ & flor & $\mathrm{MeOH}$ & Microdiluição & $\begin{array}{c}\mathrm{CIM}(\mathrm{mg} / \mathrm{mL}) \\
\text { P. gingivalis 1: } 20,83 \\
\text { P. gingivalis 2: } 0,97 \\
\text { P. gingivalis 3: } 0,73\end{array}$ & $\begin{array}{l}\text { lauk et al., } \\
2002\end{array}$ \\
\hline \multirow[t]{5}{*}{ Compositae } & $\begin{array}{l}\text { Calendula } \\
\text { officinalis L. }\end{array}$ & $\mathrm{NI}$ & flor & $\mathrm{MeOH}$ & Microdiluição & $\begin{array}{c}\mathrm{CIM}(\mathrm{mg} / \mathrm{mL}) \\
\text { P. gingivalis } 4: 0,32 \\
\text { P. gingivalis } 5 \geq 163,84 \\
\text { F. nucleatum } \geq 163,84\end{array}$ & $\begin{array}{l}\text { lauk et al., } \\
2002\end{array}$ \\
\hline & $\begin{array}{l}\text { Chrysanthemum } \\
\text { indicum L. }\end{array}$ & Coreia & $\begin{array}{l}\text { parte } \\
\text { aérea }\end{array}$ & $\mathrm{H}_{2} \mathrm{O}$ & $\begin{array}{l}\text { Diluição em } \\
\text { caldo }\end{array}$ & $\begin{array}{c}\text { CIM (mg/mL) } \\
\text { S. mutans (ATCC 25175): 0,4 } \\
\text { S. sanguinis (ATCC 10556): 0,4 } \\
\text { S. sobrinus (ATCC 27607): 0,4 } \\
\text { F. nucleatum (ATCC 10953): 0,2 } \\
\text { P. intermedia (ATCC 25611): 0,2 } \\
\text { P. gingivalis (ATCC 33277): 0,1 }\end{array}$ & Jung, 2009 \\
\hline & $\begin{array}{l}\text { Matricaria recutita } \\
\qquad \mathrm{L} .\end{array}$ & 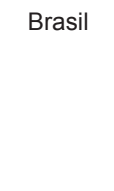 & flor & $\mathrm{EtOH}-\mathrm{H}_{2} \mathrm{O}$ & $\begin{array}{l}\text { Diluição em } \\
\text { caldo }\end{array}$ & $\begin{array}{l}\text { CIMA (mg/mL) } \\
\text { S. mutans (ATCC 25175): 0,25 } \\
\text { S. sanguinis (ATCC 10557): } \\
0,125 \\
\text { L. casei (ATCC 7469): 0,25 }\end{array}$ & $\begin{array}{l}\text { Albuquerque } \\
\text { et al., } 2010\end{array}$ \\
\hline & $\begin{array}{c}\text { Solidago } \\
\text { microglossa DC. }\end{array}$ & Brasil & $\begin{array}{l}\text { parte } \\
\text { aérea }\end{array}$ & $\mathrm{EtOH}$ & Microdiluição & $\begin{array}{l}\text { CIM }(\mathrm{mg} / \mathrm{mL}) \\
\text { S. mutans (ATCC 25175): 7,81 } \\
\text { L. casei (ATCC 7469): 1,95 }\end{array}$ & $\begin{array}{l}\text { Freires et al., } \\
2010\end{array}$ \\
\hline & $\begin{array}{c}\text { Vernonia } \\
\text { amygdalina L. }\end{array}$ & Índia & folha & $\begin{array}{l}\mathrm{MeOH} \\
\mathrm{EtOH} \\
\mathrm{H}_{2} \mathrm{O}\end{array}$ & $\begin{array}{l}\text { Difusão em } \\
\text { ágar }\end{array}$ & $\begin{array}{c}\text { Halo de inibição }(\mathrm{mm}) \\
\text { S. mutans: } 14,54 \\
\text { S. aureus: } 22,5 \\
\text { L. acidophilus: NA } \\
\text { Halo de inibição (mm) } \\
\text { S. mutans: } 29,32 \\
\text { S. aureus: } 11,31 \\
\text { Halo de inibição }(\mathrm{mm}) \\
\text { S. mutans: } 33,98 \\
\text { S. aureus: } 19,61 \\
\text { L. acidophilus: } 19,65\end{array}$ & $\begin{array}{c}\text { Sharma \& } \\
\text { Sharma, } \\
2010\end{array}$ \\
\hline Chrysobalanceae & $\begin{array}{c}\text { Parinari } \\
\text { curatellifolia } \\
\text { Planch }\end{array}$ & $\begin{array}{l}\text { África do } \\
\text { Sul }\end{array}$ & casca & $\mathrm{EtOH}$ & $\begin{array}{l}\text { Difusão em } \\
\text { ágar }\end{array}$ & $\begin{array}{c}\text { Halo de inibição }(\mathrm{mm} \text { ) } \\
\text { S. mutans (ATCC 25175): 3,6 } \\
\text { P. gingivalis (ATCC 33277): 3,0 } \\
\text { P. intermedia (ATCC 25611): 2,4 } \\
\text { CIM (mg/mL) } \\
\text { S. mutans (ATCC 25175): 6,3 } \\
\text { P. gingivalis (ATCC 33277): 3,1 } \\
\text { P. intermedia (ATCC 25611): NA }\end{array}$ & $\begin{array}{c}\text { More et al., } \\
2008\end{array}$ \\
\hline Clusiaceae & $\begin{array}{c}\text { Cratoxylum } \\
\text { formosum Dyer }\end{array}$ & Tailândia & $\begin{array}{l}\text { casca do } \\
\text { caule }\end{array}$ & $\mathrm{H}_{2} \mathrm{O}$ & $\begin{array}{l}\text { Difusão em } \\
\text { ágar }\end{array}$ & $\begin{array}{l}\text { Halo de inibição (mm) } \\
\text { S. mutans (KPSK2): 11,5 } \\
\text { CIM (mg/mL) } \\
\text { S. mutans (KPSK2): 0,048 }\end{array}$ & $\begin{array}{c}\text { Suddhasthira } \\
\text { et al., } 2006\end{array}$ \\
\hline Clusiaceae & $\begin{array}{c}\text { Rheedia } \\
\text { gardneriana } \\
\text { Planch. \& Triana }\end{array}$ & Brasil & semente & $\mathrm{EtOH}-\mathrm{H}_{2} \mathrm{O}$ & $\begin{array}{l}\text { Difusão em } \\
\text { ágar }\end{array}$ & $\begin{array}{l}\text { Halo de inibição }(\mathrm{mm}) \\
\text { S. mutans (ATCC 700610): NA }\end{array}$ & $\begin{array}{l}\text { Samarão et } \\
\text { al., } 2010\end{array}$ \\
\hline
\end{tabular}


TABELA 2. Extratos vegetais e frações com estudos de avaliação da atividade antimicrobiana in vitro sobre patógenos orais, com indicação da origem do material vegetal, preparação, método e microrganismo testado

continuação..

\begin{tabular}{|c|c|c|c|c|c|c|c|}
\hline Família & Nome botânico & Origem & $\begin{array}{c}\text { Parte } \\
\text { usada }\end{array}$ & Preparação & Método & Microrganismo/ Resultado & Referências \\
\hline & & & & $\mathrm{CH}_{2} \mathrm{Cl}_{2}$ & & Halo de inibição (mm) & \\
\hline & & & & & & S. mutans (ATCC 700610): 17,7 & \\
\hline & & & & Fração de & & Halo de inibição (mm) & \\
\hline & & & & Hex & & S. mutans (ATCC 700610): 19,33 & \\
\hline & & & & Fração de & & Halo de inibição (mm) & \\
\hline & & & & $\mathrm{MeOH}$ & & S. mutans (ATCC 700610): 27,83 & \\
\hline \multirow[t]{23}{*}{ Combretaceae } & Anogeissus & Nigéria & raiz & $\mathrm{EtOH}$ & Difusão em & Halo de inibição (mm) & Adejumobi et \\
\hline & leiocarpus (DC.) & & & & ágar & S. mutans: 40,0 & al., 2008 \\
\hline & Guill. \& Perr. & & & & & & \\
\hline & & & & $\mathrm{H}_{2} \mathrm{O}$ & & Halo de inibição (mm) & \\
\hline & & & & & & S. mutans: 29,5 & \\
\hline & & & caule & $\mathrm{EtOH}$ & & Halo de inibição (mm) & \\
\hline & & & & & & S. mutans: 29,0 & \\
\hline & & & & $\mathrm{H}_{2} \mathrm{O}$ & & Halo de inibição (mm) & \\
\hline & & & & & & S. mutans: 25,0 & \\
\hline & Terminalia chebula & Índia & fruto & $\mathrm{MeOH}$ & Difusão em & Halo de inibição (mm) & Aneja e \\
\hline & Retz & & & & ágar & S. mutans (MTCC 497): 20,96 & Joshi, 2009 \\
\hline & & & & & & S. aureus (MTCC 740): 23,65 & \\
\hline & & & & $\mathrm{EtOH}$ & & Halo de inibição (mm) & \\
\hline & & & & & & S. mutans (MTCC 497): 22,65 & \\
\hline & & & & & & S. aureus (MTCC 740): 31,32 & \\
\hline & & & & & & L. acidophilus (MTCC 447): NA & \\
\hline & & & & AcE & & Halo de inibição (mm) & \\
\hline & & & & & & S. mutans (MTCC 497): 25,32 & \\
\hline & & & & & & S. aureus (MTCC 740): 32,97 & \\
\hline & & & & & & L. acidophilus (MTCC 447): NA & \\
\hline & & & & $\mathrm{H}_{2} \mathrm{O}$ & & Halo de inibição (mm) & \\
\hline & & & & & & S. mutans (MTCC 497): 21,96 & \\
\hline & & & & & & S. aureus (MTCC 740): 27,97 & \\
\hline \multirow[t]{8}{*}{ Ebenaceae } & Euclea divinorum & África do & folha e & $\mathrm{EtOH}$ & Difusão em & Halo de inibição (mm) & More et al., \\
\hline & Hiern & Sul & casca & & ágar & S. mutans (ATCC 25175): 6,0 & 2008 \\
\hline & & & & & & P. gingivalis (ATCC 33277): 6,5 & \\
\hline & & & & & & P. intermedia: NA & \\
\hline & & & & & & $\mathrm{CIM}(\mathrm{mg} / \mathrm{mL})$ & \\
\hline & & & & & & S. mutans (ATCC 25175): 25,0 & \\
\hline & & & & & & P. gingivalis (ATCC 33277): 3,1 & \\
\hline & & & & & & P. intermedia (ATCC 25611): NA & \\
\hline \multirow[t]{8}{*}{ Ebenaceae } & Euclea natalensis & África do & folha & $\mathrm{EtOH}$ & Difusão em & Halo de inibição (mm) & More et al., \\
\hline & A.DC. & Sul & & & ágar & S. mutans (ATCC 25175): 6,8 & 2008 \\
\hline & & & & & & P. gingivalis (ATCC 33277): 3,5 & \\
\hline & & & & & & P. intermedia (ATCC 25611): 4,5 & \\
\hline & & & & & & $\mathrm{CIM}(\mathrm{mg} / \mathrm{mL})$ & \\
\hline & & & & & & S. mutans (ATCC 25175): 6,3 & \\
\hline & & & & & & P. gingivalis (ATCC 33277): 6,3 & \\
\hline & & & & & & P. intermedia (ATCC 25611): 6,3 & \\
\hline \multirow[t]{8}{*}{ Fabaceae } & Stryphnodendron & Brasil & casca do & $\mathrm{EtOH}-\mathrm{H}_{2} \mathrm{O}$ & Diluição em & $\operatorname{CIM}(\mathrm{mg} / \mathrm{mL})$ & Soares et al., \\
\hline & adstringens Mart. & & caule & & caldo & S. mutans (ATCC 25175) >0,4 & 2008 \\
\hline & & & & & & S. sanguinis (ATCC 10556) > 0,4 & \\
\hline & & & & & & S. sobrinus (ATCC 33478) > 0,4 & \\
\hline & & & & & & S. mitis (ATCC 49456): 0,35 & \\
\hline & & & & & & S. salivaris (ATCC 25975) >0,4 & \\
\hline & & & & & & E. faecalis (ATCC 4082) > 0,4 & \\
\hline & & & & & & L. casei (ATCC 11578): 0,35 & \\
\hline
\end{tabular}


TABELA 2. Extratos vegetais e frações com estudos de avaliação da atividade antimicrobiana in vitro sobre patógenos orais, com indicação da origem do material vegetal, preparação, método e microrganismo testado

continuação..

\begin{tabular}{|c|c|c|c|c|c|c|c|}
\hline Família & Nome botânico & Origem & $\begin{array}{l}\text { Parte } \\
\text { usada }\end{array}$ & Preparação & Método & Microrganismo/ Resultado & Referências \\
\hline \multirow[t]{2}{*}{ Flacourtiaceae } & $\begin{array}{l}\text { Casearia sylvestris } \\
\text { Sw. }\end{array}$ & Brasil & flor e folha & $\mathrm{H}_{2} \mathrm{O}$ & $\begin{array}{l}\text { Difusão em } \\
\text { ágar }\end{array}$ & $\begin{array}{l}\text { Halo de inibição }(\mathrm{mm}) \\
\text { S. mutans (ATCC 25175): 12,0 } \\
\text { L. casei: } 9,0\end{array}$ & $\begin{array}{l}\text { Nogueira et } \\
\text { al., } 2007\end{array}$ \\
\hline & & Brasil & folha & $\mathrm{EtOH}$ & $\begin{array}{l}\text { Diluição em } \\
\text { ágar }\end{array}$ & $\begin{array}{c}\mathrm{CIM}(\mathrm{mg} / \mathrm{mL}) \\
\text { S. mutans (ATCC } 70069): 0,005 \\
\text { A. actinomycetemcomitans (ATCC } \\
\text { 33384)>0,001 } \\
\text { P. gingivalis (ATCC 33277) > } \\
0,001 \\
\text { F. nucleatum (ATCC 31647): } 0,008\end{array}$ & $\begin{array}{l}\text { Tavares et } \\
\text { al., } 2009\end{array}$ \\
\hline Hamamelidaceae & $\begin{array}{l}\text { Hamamelis } \\
\text { virginiana } \mathrm{L} \text {. }\end{array}$ & $\mathrm{NI}$ & folha & $\mathrm{MeOH}$ & Microdiluição & $\begin{array}{l}\text { CIM (mg/mL) } \\
\text { P. gingivalis1: } 15,62 \\
\text { P. gingivalis } 2: 7,81 \\
\text { P. gingivalis } 3: 11,71 \\
\text { P. gingivalis 4: } 7,81 \\
\text { P. gingivalis 5: } 2,44 \\
\text { F. nucleatum: } 16,384\end{array}$ & $\begin{array}{l}\text { lauk et al., } \\
2002\end{array}$ \\
\hline Labiatae & $\begin{array}{l}\text { Rosmarinus } \\
\text { officinalis L. }\end{array}$ & Brasil & $\begin{array}{l}\text { folha e } \\
\text { caule }\end{array}$ & $\mathrm{EtOH}-\mathrm{H}_{2} \mathrm{O}$ & $\begin{array}{l}\text { Difusão em } \\
\text { ágar }\end{array}$ & $\begin{array}{l}\text { Halo de inibição (mm) } \\
\text { S. mutans (ATCC 25175): 18,0 } \\
\text { S. mitis (ATCC 98811): NA } \\
\text { S. sanguinis (ATCC 10556): 15,0 } \\
\text { S. sobrinus (ATCC 27609): 15,0 } \\
\text { L. casei (ATCC 7469): 17,0 }\end{array}$ & $\begin{array}{c}\text { Silva et al., } \\
2008\end{array}$ \\
\hline Lamiaceae & $\begin{array}{l}\text { Lavandula } \\
\text { angustifolia Mill. }\end{array}$ & Brasil & flor e folha & $\mathrm{H}_{2} \mathrm{O}$ & $\begin{array}{l}\text { Difusão em } \\
\text { ágar }\end{array}$ & $\begin{array}{c}\text { Halo de inibição (mm) } \\
\text { S. mutans (ATCC } 25175) \text { : NA } \\
\text { L. casei: 12,0 (flor) } \\
10,0 \text { (folha) }\end{array}$ & $\begin{array}{l}\text { Nogueira et } \\
\text { al., } 2007\end{array}$ \\
\hline \multirow[t]{6}{*}{ Lamiaceae } & $\begin{array}{c}\text { Melissa officinalis } \\
\text { L. }\end{array}$ & $\mathrm{NI}$ & folha & $\mathrm{MeOH}$ & Microdiluição & $\begin{array}{c}\text { CIM }(\mathrm{mg} / \mathrm{mL}) \\
\text { P. gingivalis } 1: 0,48 \\
\text { P. gingivalis } 2 \text { e } 4: 0,97 \\
\text { P. gingivalis } 3: 1,46 \\
\text { P. gingivalis } 5: 0,30 \\
\text { F. nucleatum } \geq 16,384\end{array}$ & $\begin{array}{l}\text { lauk et al., } \\
2002\end{array}$ \\
\hline & & Brasil & flor e folha & $\mathrm{H}_{2} \mathrm{O}$ & $\begin{array}{l}\text { Difusão em } \\
\text { ágar }\end{array}$ & $\begin{array}{c}\text { Halo de inibição }(\mathrm{mm}) \\
\text { S. mutans (ATCC } 25175) \text { : NA } \\
\text { L. casei: } 8,0\end{array}$ & $\begin{array}{l}\text { Nogueira et } \\
\text { al., } 2007\end{array}$ \\
\hline & & $\mathrm{NI}$ & $\mathrm{NI}$ & $\mathrm{EtOH}$ & $\begin{array}{l}\text { Diluição em } \\
\text { caldo }\end{array}$ & $\begin{array}{c}\text { CIM }(\mathrm{mg} / \mathrm{mL}) \\
\text { S. mutans (ATCC } 1 \text { 27607): 0,31 } \\
\text { S. sanguis (PTCC 1449): 0,31 }\end{array}$ & $\begin{array}{l}\text { Babpour et } \\
\text { al., } 2009\end{array}$ \\
\hline & Mentha piperita L. & Brasil & flor e folha & $\mathrm{H}_{2} \mathrm{O}$ & $\begin{array}{l}\text { Difusão em } \\
\text { ágar }\end{array}$ & $\begin{array}{l}\text { Halo de inibição }(\mathrm{mm}) \\
\text { S. mutans (ATCC } 25175): 7,0 \\
\text { L. casei: } 15,0\end{array}$ & $\begin{array}{l}\text { Nogueira et } \\
\text { al., } 2007\end{array}$ \\
\hline & $\begin{array}{c}\text { Mentha pulegium } \\
\text { L. }\end{array}$ & Brasil & flor e folha & $\mathrm{H}_{2} \mathrm{O}$ & $\begin{array}{l}\text { Difusão em } \\
\text { ágar }\end{array}$ & $\begin{array}{l}\text { Halo de inibição }(\mathrm{mm}) \\
\text { S. mutans (ATCC 25175): 9,0 }\end{array}$ & \\
\hline & $\begin{array}{c}\text { Ocimum } \\
\text { americanum L. }\end{array}$ & Tailândia & folha & $\mathrm{H}_{2} \mathrm{O}$ & $\begin{array}{l}\text { Difusão em } \\
\text { ágar }\end{array}$ & $\begin{array}{l}\text { Halo de inibição (mm) } \\
\text { S. mutans (KPSK2): 28,0 } \\
\text { L. casei (ATCC 6363): 19,0 }\end{array}$ & $\begin{array}{c}\text { Thaweboon \& } \\
\text { Thaweboon, } \\
2009 \\
\end{array}$ \\
\hline Lauraceae & $\begin{array}{l}\text { Cinnamomum } \\
\text { zeylanicum L. }\end{array}$ & Brasil & $\begin{array}{l}\text { casca do } \\
\text { caule }\end{array}$ & $\mathrm{H}_{2} \mathrm{O}$ & $\begin{array}{c}\text { Difusão em } \\
\text { ágar }\end{array}$ & $\begin{array}{c}\text { Halo de inibição }(\mathrm{mm}) \\
\text { S. mutans (ATCC 25175): 24,0 } \\
\text { L. casei: NA }\end{array}$ & $\begin{array}{c}\text { Nogueira et } \\
\text { al., } 2007\end{array}$ \\
\hline
\end{tabular}


TABELA 2. Extratos vegetais e frações com estudos de avaliação da atividade antimicrobiana in vitro sobre patógenos orais, com indicação da origem do material vegetal, preparação, método e microrganismo testado

continuação..

\begin{tabular}{|c|c|c|c|c|c|c|c|}
\hline Família & Nome botânico & Origem & $\begin{array}{l}\text { Parte } \\
\text { usada }\end{array}$ & Preparação & Método & Microrganismo/ Resultado & Referências \\
\hline \multirow[t]{17}{*}{ Leguminosae } & Caesalpinia ferrea & Brasil & fruto & $\mathrm{MeOH}$ & Microdiluição & $\mathrm{CIM}(\mathrm{mg} / \mathrm{mL})$ & Sampaio et \\
\hline & Martius & & & & & S. mutans (ATCC 25175): 0,04 & al., 2009 \\
\hline & & & & & & S. salivaris (ATCC 7073): 0,066 & \\
\hline & & & & & & S. oralis (ATCC 10557): 0,100 & \\
\hline & & & & & & L. casei (ATCC 7469): 0,066 & \\
\hline & Caesalpinia & Brasil & folha & $\mathrm{H}_{2} \mathrm{O}$ & Diluição em & $\mathrm{CIM}(\mathrm{mg} / \mathrm{mL})$ & Alviano et al., \\
\hline & pyramidalis Tul. & & & & caldo & S. mutans (ATCC 25175): 8,0 & 2008 \\
\hline & & & & & & P. intermedia (ATCC 25611): 1,0 & \\
\hline & & & & & & P. gingivalis (ATCC 49417): 1,0 & \\
\hline & & & & & & F. nucleatum (ATCC 25586): 1,0 & \\
\hline & & & & & & L. casei (ATCC 4646): 8,0 & \\
\hline & Koompassia & Indonésia & $\mathrm{NI}$ & $\mathrm{EtOH}-\mathrm{H}_{2} \mathrm{O}$ & Microdiluição & $\mathrm{CIM}(\mathrm{mg} / \mathrm{mL})$ & Kuspradini, et \\
\hline & malaccensis Benth. & & & & & S. sobrinus (6715): 0,225 & al., 2009 \\
\hline & Stryphnodendron & Brasil & casca do & $\mathrm{EtOH}$ & Diluição e & $\mathrm{CIM}(\mathrm{mg} / \mathrm{mL})$ & \\
\hline & adstringens (Mart.) & & caule & & difusão em & S. mutans (ATCC 70069): & 0,003 \\
\hline & Coville & & & & ágar & S. aureus (ATCC 12692): & 0,004 \\
\hline & & & & & & A. actinomycetemcomitans (ATCC & 29522): 0,005 \\
\hline \multirow[t]{14}{*}{ Liliaceae } & Allium sativum $\mathrm{L}$. & $\mathrm{NI}$ & fruto & $\mathrm{H}_{2} \mathrm{O}$ & Diluição em & $\mathrm{CIM}(\mathrm{mg} / \mathrm{mL})$ & Bakri \& \\
\hline & & & & & caldo & S. mutans Ingbritt: 0,0275 & Douglas, \\
\hline & & & & & & S. sanguis (NCTC 7863): 0,0275 & 2005 \\
\hline & & & & & & S. mitis (NCTC 10712): 0,0275 & \\
\hline & & & & & & S. oralis (NCTC 7864): 0,0275 & \\
\hline & & & & & & P. intermedia (ATCC 25611): & \\
\hline & & & & & & 0,001 & \\
\hline & & & & & & P. gingivalis (W50): 0,0017 & \\
\hline & & & & & & F. nucleatum (NCTC 11326): & \\
\hline & & & & & & 0,004 & \\
\hline & & $\mathrm{NI}$ & fruto & $\mathrm{H}_{2} \mathrm{O}$ & Diluição e & $\mathrm{CIM}(\mathrm{mg} / \mathrm{mL})$ & Fani et al., \\
\hline & & & & & disco difusão & S. mutans (IC): 0,0016 & 2007 \\
\hline & & & & & & Halo de inibição (mm) & \\
\hline & & & & & & S. mutans: 22,0 a 44,0 & \\
\hline \multirow[t]{11}{*}{ Malvaceae } & Althaea officinalis & $\mathrm{NI}$ & raiz & $\mathrm{MeOH}$ & Microdiluição & $\mathrm{CIM}(\mathrm{mg} / \mathrm{mL})$ & lauk et al., \\
\hline & L. & & & & & P. gingivalis 1 e 4: 0,97 & 2002 \\
\hline & & & & & & P. gingivalis 2: 1,95 & \\
\hline & & & & & & P. gingivalis $3: 1,46$ & \\
\hline & & & & & & P. gingivalis $5: 1,22$ & \\
\hline & & & & & & F. nucleatum $\geq 163,84$ & \\
\hline & Malva sylvestris L. & Brasil & folha & $\mathrm{NI}$ & Difusão em & $\mathrm{CIM}(\mathrm{mg} / \mathrm{mL})$ & Alves et al., \\
\hline & & & & & meio sólido & S. mutans: 0,25 & 2009 \\
\hline & & & & & & S. mitis: 1,0 & \\
\hline & & & & & & S. sanguis: 0,5 & \\
\hline & & & & & & S. sobrinus: 0,25 & \\
\hline \multirow[t]{5}{*}{ Meliaceae } & Azadirachta indica & Índia & parte & $\mathrm{H}_{2} \mathrm{O}$ & Difusão em & Halo de inibição (mm) & Prashant et \\
\hline & A. Juss. & & aérea & & ágar & S. mutans (MTCC 890): 2,4 & al., 2007 \\
\hline & & & & & & S. salivaris (ATCC 9222): 1,5 & \\
\hline & & & & & & S. mitis (MTCC 2695): 1,5 & \\
\hline & & & & & & S. sanguis (ATCC 10556): 2,0 & \\
\hline \multirow[t]{6}{*}{ Mimosaceae } & Mimosa tenuiflora & Brasil & casca & $\mathrm{MeOH}$ & Difusão em & Halo de inibição (mm) & Macêdo- \\
\hline & (Willd.) Poir. & & & & ágar & S. mitis (ATCC 9811): 20,0 & Costa et al., \\
\hline & . & & & & & S. mutans (ATCC 25175): 20,0 & 2009 \\
\hline & & & & & & S. sanguinis (ATCC 10557): 19,0 & \\
\hline & & & & & & S. sobrinus (ATCC 27609): 20,0 & \\
\hline & & & & & & L. casei (ATCC 7469): 19,0 & \\
\hline
\end{tabular}

continua...

Rev. Bras. PI. Med., Campinas, v.16, n.1, p.135-167, 2014. 
TABELA 2. Extratos vegetais e frações com estudos de avaliação da atividade antimicrobiana in vitro sobre patógenos orais, com indicação da origem do material vegetal, preparação, método e microrganismo testado

continuação...

\begin{tabular}{|c|c|c|c|c|c|c|c|}
\hline Família & Nome botânico & Origem & $\begin{array}{l}\text { Parte } \\
\text { usada }\end{array}$ & Preparação & Método & Microrganismo/ Resultado & Referências \\
\hline Moraceae & Ficus carica L. & Coreia & folha & $\mathrm{MeOH}$ & $\begin{array}{l}\text { Diluição em } \\
\text { caldo }\end{array}$ & $\begin{array}{c}\text { CIM (mg/mL) } \\
\text { S. mutans (ATCC 25175): 1,25 } \\
\text { S. sanguinis (ATCC 10556): 2,5 } \\
\text { S. sobrinus (ATCC 27607): 1,25 } \\
\text { F. nucleatum (ATCC 51190): 1,25 } \\
\text { P. intermedia (ATCC 49046): } \\
\text { 0,313 } \\
\text { P. gingivalis (ATCC 33277): 0,625 }\end{array}$ & $\begin{array}{c}\text { Jeong et al., } \\
2009\end{array}$ \\
\hline Myristicaceae & $\begin{array}{c}\text { Myristica fragrans } \\
\text { Houtt. }\end{array}$ & Indonésia & semente & $\mathrm{MeOH}$ & $\begin{array}{l}\text { Diluição em } \\
\text { caldo }\end{array}$ & $\begin{array}{l}\text { CIM (mg/mL) } \\
\text { S. mutans (ATCC 25175): 0,0039 } \\
\text { S. sobrinus (ATCC 27351): } \\
0,0156 \\
\text { S. sanguis (ATCC 35105): 0,002 } \\
\text { S. salivarius (KCCM 40412): } \\
0,0313 \\
\text { L. acidophilus (KCCM 32820): } \\
\text { 0,002 } \\
\text { L. casei (KCCM } 35465): 0,0039 \\
\text { P. gingivalis (ATCC 53978): } 0,125\end{array}$ & $\begin{array}{c}\text { Chung et al., } \\
2006\end{array}$ \\
\hline Myrtaceae & $\begin{array}{l}\text { Myrciaria cauliflora } \\
\text { (Mart.) O.Berg. }\end{array}$ & Brasil & folha & $\mathrm{EtOH}$ & $\begin{array}{l}\text { Difusão em } \\
\text { meio sólido }\end{array}$ & $\begin{array}{l}\text { Halo de inibição }(\mathrm{mm}) \\
\text { S. mutans (ATCC 25175): 12,0 } \\
\text { S. sanguis (ATCC 10557): 13,0 }\end{array}$ & $\begin{array}{l}\text { Carvalho et } \\
\text { al., } 2009\end{array}$ \\
\hline & Psidium guajava L. & Brasil & folha & $\mathrm{EtOH}-\mathrm{H}_{2} \mathrm{O}$ & $\begin{array}{l}\text { Difusão em } \\
\text { disco }\end{array}$ & $\begin{array}{l}\text { Halo de inibição }(\mathrm{mm}) \\
\text { S. oralis: } 20,0 \\
\text { S. mitis: } 20,0\end{array}$ & $\begin{array}{c}\text { Menezes et } \\
\text { al., } 2004\end{array}$ \\
\hline & & Brasil & folha & $\mathrm{EtOH}$ & $\begin{array}{l}\text { Difusão em } \\
\text { meio sólido }\end{array}$ & $\begin{array}{c}\text { CIM (mg/mL) } \\
\text { S. mutans: } 0,031 \\
\text { S. mitis: } 0,25 \\
\text { S. sanguis: } 0,25 \\
\text { S. sobrinus: } 0,062 \\
\text { L. casei: } 0,062\end{array}$ & $\begin{array}{l}\text { Alves et al., } \\
2009\end{array}$ \\
\hline Myrtaceae & $\begin{array}{c}\text { Syzygium } \\
\text { aromaticum L. }\end{array}$ & $x^{2}$ & 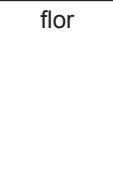 & $\mathrm{MeOH}$ & $\begin{array}{l}\text { Diluição em } \\
\text { caldo }\end{array}$ & $\begin{array}{c}\text { CIM }(\mathrm{mg} / \mathrm{mL}) \\
\text { S. } \text { mutans Ingbritt }>2,5 \\
\text { A. viscosus (W1053) }>2,5 \\
\text { P. intermedia: } 0,156 \\
\text { P. gingivalis (ATCC 33277): } 0,625\end{array}$ & $\begin{array}{l}\text { Cai \& Wu, } \\
1996\end{array}$ \\
\hline & & Brasil & fruto & $\mathrm{H}_{2} \mathrm{O}$ & $\begin{array}{l}\text { Difusão em } \\
\text { ágar }\end{array}$ & $\begin{array}{l}\text { Halo de inibição (mm) } \\
\text { S. mutans (ATCC 25175): 9,0 } \\
\text { L. casei: } 7,0\end{array}$ & $\begin{array}{l}\text { Nogueira et } \\
\text { al., } 2007\end{array}$ \\
\hline Palmae & Cocos nucifera L. & Brasil & casca & $\mathrm{H}_{2} \mathrm{O}$ & $\begin{array}{l}\text { Diluição em } \\
\text { caldo }\end{array}$ & $\begin{array}{c}\text { CIM }(\mathrm{mg} / \mathrm{mL}) \\
\text { S. mutans (ATCC 25175): 4,0 } \\
\text { P. intermedia (ATCC 25611): 2,0 } \\
\text { P. gingivalis (ATCC 49417): 0,2 } \\
\text { L. casei (ATCC 4646): } 8,0\end{array}$ & $\begin{array}{l}\text { Alviano et al., } \\
2008\end{array}$ \\
\hline Pedaliaceae & $\begin{array}{c}\text { Dicerocarym } \\
\text { senecioides } \\
\text { (Klotzsch) Abels. }\end{array}$ & $\begin{array}{l}\text { África do } \\
\text { Sul }\end{array}$ & raiz & $\mathrm{EtOH}$ & $\begin{array}{l}\text { Microdiluição } \\
\text { e difusão em } \\
\text { ágar }\end{array}$ & $\begin{array}{l}\text { Halo de inibição (mm) } \\
\text { S. mutans (ATCC 25175): 3,5 } \\
\text { P. gingivalis (ATCC 33277): 4,5 } \\
\text { P. intermedia (ATCC 25611): 3,6 } \\
\text { CIM (mg/mL) } \\
\text { S. mutans (ATCC 25175): 12,5 } \\
\text { P. gingivalis (ATCC 33277): 0,8 } \\
\text { P. intermedia (ATCC 25611): NA }\end{array}$ & $\begin{array}{l}\text { More et al., } \\
2008\end{array}$ \\
\hline
\end{tabular}


TABELA 2. Extratos vegetais e frações com estudos de avaliação da atividade antimicrobiana in vitro sobre patógenos orais, com indicação da origem do material vegetal, preparação, método e microrganismo testado

continuação...

\begin{tabular}{|c|c|c|c|c|c|c|c|}
\hline Família & Nome botânico & Origem & $\begin{array}{l}\text { Parte } \\
\text { usada }\end{array}$ & Preparação & Método & Microrganismo/ Resultado & Referências \\
\hline Phytolaccacea & $\begin{array}{c}\text { Petiveria alliacea } \\
\text { L. }\end{array}$ & Brasil & folha & $\mathrm{EtOH}$ & Microdiluição & $\begin{array}{c}\text { CIM }(\mathrm{mg} / \mathrm{mL}) \\
\text { S. aureus (ATCC 25923): 3,96 } \\
\text { E. faecalis (ATCC 29212): 3,96 } \\
\text { S. mutans (ATCC 27175): 3,96 } \\
\text { B. subtilis (ATCC 6633): 3,96 } \\
\text { E. coli (ATCC 25922): 3,96 } \\
\text { P. aeruginosa (ATCC 27853): } \\
3,96\end{array}$ & $\begin{array}{l}\text { Guedes et } \\
\text { al., } 2009\end{array}$ \\
\hline Piperaceae & Piper betle L. & Malásia & folha & $\mathrm{H}_{2} \mathrm{O}$ & $\begin{array}{l}\text { Análise de } \mathrm{pH} \\
\text { e microscopia } \\
\text { eletrônica }\end{array}$ & $\begin{array}{l}\text { S. mutans (ATCC 25175): } \\
\text { redução de pH e alterações } \\
\text { estruturais }\end{array}$ & $\begin{array}{c}\text { Nalina \& } \\
\text { Rahim, } 2007\end{array}$ \\
\hline Plantaginaceae & Plantago major L. & $\mathrm{NI}$ & folha e flor & $\mathrm{EtOH}$ & $\begin{array}{c}\text { Difusão em } \\
\text { ágar }\end{array}$ & $\begin{array}{c}\text { Halo de inibição (mm) } \\
\text { S. aureus: NA } \\
\text { E. faecalis: NA } \\
\text { Streptococcus sp.: NA } \\
\text { B. subtilis: NA } \\
\text { E. coli: NA } \\
\text { K. pneumoniae: } 20,0\end{array}$ & $\begin{array}{c}\text { Santos et al., } \\
2007\end{array}$ \\
\hline Poaceae & $\begin{array}{c}\text { Cimbopogum } \\
\text { nardus (L.) Rendle }\end{array}$ & Brasil & folha & $\mathrm{H}_{2} \mathrm{O}$ & $\begin{array}{l}\text { Difusão em } \\
\text { ágar }\end{array}$ & $\begin{array}{l}\text { Halo de inibição }(\mathrm{mm}) \\
\text { S. mutans (ATCC } 25175): 25,0 \\
\text { L. casei: } 10,0\end{array}$ & $\begin{array}{c}\text { Nogueira et } \\
\text { al., } 2007\end{array}$ \\
\hline Polygonaceae & $\begin{array}{l}\text { Polygonum } \\
\text { cuspidatum Sieb. } \\
\text { \& Zucc. }\end{array}$ & Coreia & raiz & $\begin{array}{c}\mathrm{MeOH} \\
\text { Fração de } \\
n \text {-Hex }\end{array}$ & $\begin{array}{l}\text { Difusão em } \\
\text { ágar }\end{array}$ & $\begin{array}{l}\text { Halo de inibição (mm) } \\
\text { S. mutans (KCTC 3298): 10,5 } \\
\text { S. mutans (KCTC 3300): 8,7 } \\
\text { S. mutans (KCTC 3289): 7,9 } \\
\text { S. sobrinus (KCTC 3307): 8,8 } \\
\text { S. sobrinus (KCTC 3308): 7,0 } \\
\text { S. sanguis (KCTC 3284): 9,1 } \\
\text { L. acidophilus (KCTC 3111): 7,5 } \\
\text { P. gingivalis (ATCC 49417): 11,3 } \\
\text { P. intermedia (KCTC 3692): 8,0 } \\
\text { Halo de inibição (mm) } \\
\text { S. mutans (KCTC 3298): 17,2 } \\
\text { S. mutans (KCTC 3300): 17,2 } \\
\text { S. mutans (KCTC 3306): 7,3 } \\
\text { S. sobrinus (KCTC 3307): 9,0 } \\
\text { S. sobrinus (KCTC 3308): 6,2 } \\
\text { S. sanguis (KCTC 3284): 18,0 } \\
\text { L. acidophilus (KCTC 3111): 6,6 } \\
\text { P. gingivalis (ATCC 49417): 10,4 } \\
\text { P. intermedia (KCTC 3692): 16,6 }\end{array}$ & $\begin{array}{l}\text { Ban et al., } \\
2010\end{array}$ \\
\hline Polygonaceae & $\begin{array}{l}\text { Polygonum } \\
\text { cuspidatum Sieb. } \\
\text { \& Zucc. }\end{array}$ & Coreia & raiz & $\begin{array}{l}\text { Fração de } \\
\text { EtOAc }\end{array}$ & & $\begin{array}{l}\text { Halo de inibição (mm) } \\
\text { S. mutans (KCTC 3298): 17,7 } \\
\text { S. mutans (KCTC 3300): 22,3 } \\
\text { S. mutans (KCTC 3306): 10,5 } \\
\text { S. sobrinus (KCTC 3307): 11,7 } \\
\text { S. sobrinus (KCTC 3308): 9,0 } \\
\text { S. sanguis (KCTC 3284): 22,8 } \\
\text { L. acidophilus (KCTC 3111): 7,3 } \\
\text { P. gingivalis (ATCC 49417): 14,6 }\end{array}$ & $\begin{array}{c}\text { Ban et al., } \\
2010\end{array}$ \\
\hline
\end{tabular}


TABELA 2. Extratos vegetais e frações com estudos de avaliação da atividade antimicrobiana in vitro sobre patógenos orais, com indicação da origem do material vegetal, preparação, método e microrganismo testado

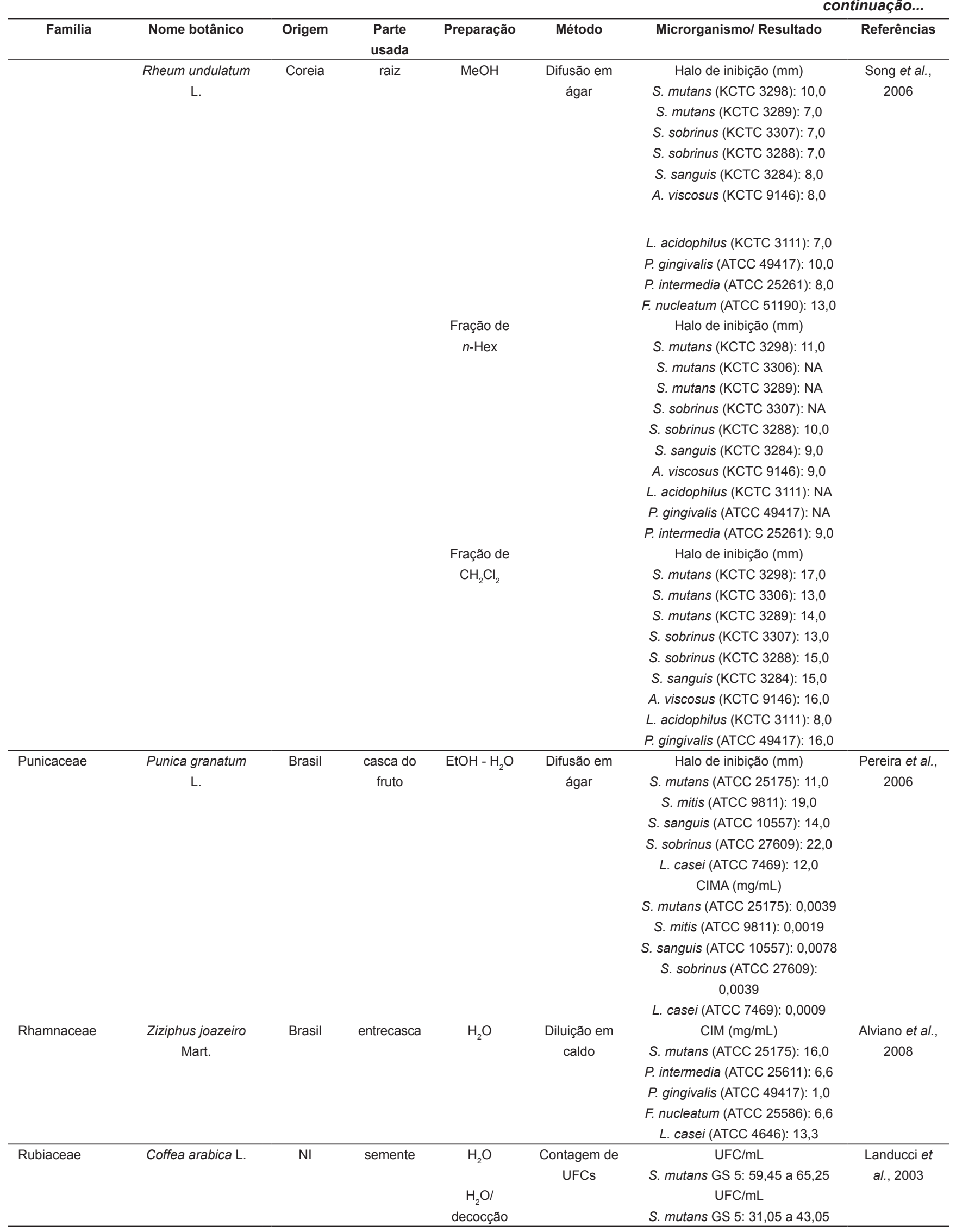


TABELA 2. Extratos vegetais e frações com estudos de avaliação da atividade antimicrobiana in vitro sobre patógenos orais, com indicação da origem do material vegetal, preparação, método e microrganismo testado

continuação..

\begin{tabular}{|c|c|c|c|c|c|c|c|}
\hline Família & Nome botânico & Origem & $\begin{array}{l}\text { Parte } \\
\text { usada }\end{array}$ & Preparação & Método & Microrganismo/ Resultado & Referências \\
\hline & $\begin{array}{l}\text { Uncaria tomentosa } \\
\text { (Willd) DC. }\end{array}$ & Peru & $\mathrm{NI}$ & $\mathrm{NI}$ & $\begin{array}{c}\text { Diluição em } \\
\text { ágar }\end{array}$ & $\begin{array}{c}\text { CIM (\%) } \\
\text { S. mutans: } 5\end{array}$ & $\begin{array}{l}\text { Ccahuana- } \\
\text { Vasquez et } \\
\text { al., } 2007\end{array}$ \\
\hline Rutaceae & $\begin{array}{l}\text { Hortia oreadica } \\
\text { Vand. ex DC. }\end{array}$ & Brasil & raiz & $n$-Hex & Microdiluição & $\begin{array}{l}\text { CIM }\left(\mathrm{mg} / \mathrm{mL}^{-1} \text { ) }\right. \\
\text { S. mutans (ATCC 25275): NA } \\
\text { S. salivaris (ATCC 25975): 0,3 } \\
\text { S. sanguinis (ATCC 10556): NA } \\
\text { S. sobrinus (ATCC 33478): NA } \\
\text { S. mitis (ATCC 49456): NA } \\
\text { L. casei (ATCC 11578): NA } \\
\text { CIM (mg/mL }{ }^{-1} \text { ) } \\
\text { S. mutans (ATCC 25275): 0,3 } \\
\text { S. salivaris (ATCC 25975): 0,2 } \\
\text { S. sanguinis (ATCC 10556): 0,2 } \\
\text { S. sobrinus (ATCC 33478): 0,3 } \\
\text { S. mitis (ATCC 49456): NA } \\
\text { L. casei (ATCC 11578): 0,4 }\end{array}$ & $\begin{array}{c}\text { Severino et } \\
\text { al., } 2009\end{array}$ \\
\hline Sapotaceae & $\begin{array}{l}\text { Englerophytum } \\
\text { magalismontanum } \\
\text { (Sond.) T.D.Penn. }\end{array}$ & $\begin{array}{l}\text { África do } \\
\text { Sul }\end{array}$ & casca & $\mathrm{EtOH}$ & $\begin{array}{l}\text { Microdiluição } \\
\text { e difusão em } \\
\text { ágar }\end{array}$ & $\begin{array}{l}\text { Halo de inibição (mm) } \\
\text { S. mutans (ATCC 25175): 3,5 } \\
\text { P. gingivalis (ATCC 33277): 4,0 } \\
\text { P. intermedia (ATCC 25611): 2,5 } \\
\text { CIM (mg/mL) } \\
\text { S. mutans (ATCC 25175): 12,5 } \\
\text { P. gingivalis (ATCC 33277): 12,5 } \\
\text { P. intermedia (ATCC 25611): NA }\end{array}$ & $\begin{array}{c}\text { More et al., } \\
2008\end{array}$ \\
\hline \multirow[t]{3}{*}{ Verbenaceae } & $\begin{array}{c}\text { Lippia alba } \\
\text { (Mill.) N.E. Brown }\end{array}$ & Brasil & flor e folha & $\mathrm{H}_{2} \mathrm{O}$ & $\begin{array}{c}\text { Difusão em } \\
\text { ágar }\end{array}$ & $\begin{array}{l}\text { Halo de inibição }(\mathrm{mm}) \\
\text { S. mutans (ATCC } 25175): 7,0 \\
\text { L. casei: } 18,0\end{array}$ & $\begin{array}{c}\text { Nogueira et } \\
\text { al., } 2009\end{array}$ \\
\hline & $\begin{array}{c}\text { Lippia sidoides } \\
\text { Cham. }\end{array}$ & Brasil & folha & $\mathrm{H}_{2} \mathrm{O}$ & $\begin{array}{l}\text { Diluição e } \\
\text { disco difusão } \\
\text { em ágar }\end{array}$ & $\begin{array}{l}\text { Halo de inibição }(\mathrm{mm}) \\
\text { S. mutans (ss-980): } 18,7 \\
\text { S. mitis: } 10,0 \\
\text { S. salivaris: } 8,5 \\
\text { S. sanguis: } 12,0 \\
\text { CIM (mg/mL) } \\
\text { S. mutans: } 5,0 \\
\text { S. mitis: } 10,0 \\
\text { S. sanguis: } 10,0 \\
\text { S. salivaris: } 10,0\end{array}$ & $\begin{array}{l}\text { Botelho et al., } \\
2007\end{array}$ \\
\hline & & Brasil & folha & $\mathrm{MeOH}$ & $\begin{array}{l}\text { Difusão em } \\
\text { meio sólido }\end{array}$ & $\begin{array}{l}\text { Halo de inibição (mm) } \\
\text { S. mitis (ATCC 9811): 20,0 } \\
\text { S. mutans (ATCC 25175): 23,0 } \\
\text { S. sanguinis (ATCC 10557): 22,0 } \\
\text { S. sobrinus (ATCC 27609): 16,0 } \\
\text { L. casei (ATCC 7469): 16,0 }\end{array}$ & $\begin{array}{l}\text { Albuquerque } \\
\text { et al., } 2008\end{array}$ \\
\hline Vitaceae & Vitis vinifera $L$. & França & semente & $\mathrm{NI}$ & Macrodiluição & $\begin{array}{l}\text { CIM (mg/mL) } \\
\text { P. gingivalis (ATCC 33277): 4,0 } \\
\text { F. nucleatum (ATCC 10953): 2,0 }\end{array}$ & $\begin{array}{c}\text { Furiga et al. } \\
2009\end{array}$ \\
\hline
\end{tabular}

CIM: Concentração Inibitória Mínima; CIMA: Concentração Inibitória Mínima de Aderência; CBM: Concentração Bactericida Mínima; IC: Isolado clínico; NA: Não ativo; $\mathrm{NI}$ : Não informado. AcE: Extrato de Acetona; $\mathrm{CHCl}_{3}$ : Extrato clorofórmico; EtOAc: Extrato de Acetato de Etil; EtOH: Extrato etanólico; EtOH - $\mathrm{H}_{2} \mathrm{O}$ : Extrato

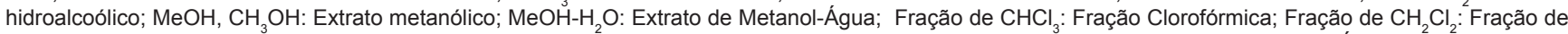
Diclorometano; Fração de EtOAc: Fração de Acetato de Etila; Fração de Hex: Fração Hexânica; Fração de MeOH-H 2 O: Fração de Metanol-Água; Fração de $n$-Hex: Fração $n$-hexânica; Hex: Extrato Hexânico; $\mathrm{H}_{2} \mathrm{O}$ : Extrato Aquoso; $n$-Hex: Extrato $n$-hexânico; UFC: Unidade Formadora de Colônia. 
2007; Araújo et al., 2009), A. sativum (Hebbar et al., 2004; Borba \& Macedo, 2006; Colvard et al., 2009), P. guajava (Hebbar et al., 2004; Borba \& Macedo, 2006), Arnica montana L. (Koo et al., 2000; lauk et al., 2002), L. sidoides (Lima Júnior et al., 2005; Albuquerque et al., 2008) e Arctium lappa L. (Pereira et al., 2005; Santos et al., 2007) representando espécies investigadas com diferentes cepas de microrganismos, parte do vegetal empregada, modo de preparação, local de coleta e/ou metodologia de estudo.

A tabela 2 demonstra, ainda, que predominam estudos de atividade biológica realizados com folhas, raízes e casca do caule. Tendo em vista que a abordagem etnofarmacológica é a principal ferramenta na seleção de espécies vegetais para estudos de validação, o predomínio do uso desses órgãos nos ensaios in vitro reflete a influência do emprego popular no delineamento experimental.

Os microrganismos mais testados foram Streptococcus orais (S. mutans, S. mitis, S. salivaris, S. sanguis, S. sobrinus e $S$. oralis) e Lactobacillus (L. casei e L. acidophilus), formadores do biofilme dental; alguns estudos avaliaram patógenos envolvidos na doença periodontal e em infecções endodônticas, tais como: Porphyromonas gingivalis, Prevotella intermedia, Fusobacterium nucleatum, Enterococcus faecalis, Staphylococcus aureus, Staphylococcus epidermidis, Actinobacillus actinomycetemcomitans e Bacillus subtilis. Foram avaliados ainda: Pseudomonas aeruginosa, Pseudomonas fluorescens, Escherichia coli, Klebsiella pneumoniae, Actinomyces naeslundii, Actinomyces israelii e Actinomyces viscosus, microrganismos também envolvidos nas infecções orais (tabelas 2 e 3 ).

A predominância de estudos com Streptococcus orais e $L$. casei é justificada pela representatividade dos mesmos na formação do biofilme. Porém as tabelas 2 e 3 demonstram variação na cepa dos microrganismos empregados para a avaliação biológica de extratos, frações e substâncias isoladas das espécies vegetais. Nesse sentido, há evidências dos diversos fatores que influenciam na virulência, crescimento e desenvolvimento in vitro de microrganismos e consequente sensibilidade ao material em teste (Thompson \& Meloni, 1993). A falta de especificação da cepa testada representa variável que dificulta a comparação de estudos futuros com a mesma espécie vegetal e/ou diferentes espécies.

Buscando identificar os princípios ativos responsáveis pela atividade antimicrobiana in vitro, estudos têm sido desenvolvidos com substâncias químicas isoladas de espécies vegetais (tabela 3). Como já referido, considerando as evidências de atuação dos óleos essenciais como antimicrobianos, diversos trabalhos foram desenvolvidos com substâncias isoladas desses constituintes (Botelho et al., 2007; Prabu et al., 2006; Al-Bayati, 2009).

A tabela 3 demonstra que 58 (cinquenta e oito) substâncias químicas foram isoladas de 19 (dezenove) espécies vegetais e submetidas a avaliação da atividade antimicrobiana in vitro; predominando os métodos de microtitulação, diluição e/ou disco-difusão em ágar. As substâncias investigadas pertencem às classes dos fenóis, flavonóides, quinonas, terpenos, cumarinas, ácidos fenólicos e compostos aromáticos policíclicos. Panduratina A, flavonóide isolado de Kaempferia pandurata Roxb. (Zingiberaceae) representa substância com valor de CIM mais expressivo para Streptococcus mutans e S. sanguis $(0,001 \mathrm{mg} / \mathrm{mL})$, apresentando resultado similar a clorexidina, agindo na prevenção e diminuição do crescimento de multiespécies de microrganismos do biofilme (Al-Bayati, 2009); ácido tetra iso-alfa, isolada de Humulus lupulus L. (Canabinaceae) representa substância com maior halo de inibição para Streptococcus mutans $(26,0 \mathrm{~mm})$.

Flavonóides isolados de diferentes espécies vegetais apresentaram expressiva atividade contra S. mutans, com valores de halo de inibição variando de 10 a $14 \mathrm{~mm}$ (Yim et al., 2010); e valores de CIM variando de 0,001 a $2,5 \mathrm{mg} / \mathrm{mL}$ (Cai \& Wu, 1996; Yanti et al., 2009).

Oito substâncias isoladas de Syzygium aromaticum L., incluindo polifenóis, terpenos, quinonas e flavonóides, apresentaram atividade contra patógenos orais, com valores de CIM entre 1,2 e $2,5 \mathrm{mg} / \mathrm{mL}$ (Cai \& Wu, 1996).

Em relação ao método de investigação, as tabelas 2 e 3 demonstram que os estudos apresentam diversas metodologias, predominando difusão em ágar para avaliação da atividade antimicrobiana e microdiluição para determinação da CIM. Ostrosky et al. (2008) indicam que o método mais conhecido de avaliação de atividade antimicrobiana de plantas é a difusão em ágar, enquanto que para determinação da CIM é utilizada a microdiluição.

A revisão dos estudos etnofarmacológicos demonstrou que diversas espécies vegetais, principalmente pertencentes à família Anacardiaceae, são empregadas na prática popular no combate a diversas afecções orais. Tendo em vista que o emprego terapêutico popular deve direcionar a seleção de espécies vegetais para pesquisa, esta revisão demonstrou que diversas espécies vegetais empregadas popularmente com finalidade terapêutica em afecções orais foram submetidas a ensaios de avaliação antimicrobiana in vitro. Os resultados desse trabalho devem estimular a 
TABELA 3. Substâncias isoladas de espécies vegetais com estudos de avaliação da atividade antimicrobiana in vitro sobre patógenos orais, com indicação do microrganismo testado e método

\begin{tabular}{|c|c|c|c|c|c|}
\hline Substância Química & Classe & Espécie Vegetal & Método & Microrganismo/Resultado & Referências \\
\hline \multirow[t]{8}{*}{$\beta$-amirina } & Terpeno & Byrsonima & Microdiluição & $\mathrm{CIM}(\mathrm{mg} / \mathrm{mL})$ & Rivero-Cruz et al., \\
\hline & & crassifolia L. & & S. aureus (375): 0,51 & 2009 \\
\hline & & & & S. aureus (ATCC 25923): 0,25 & \\
\hline & & & & B. subtilis (327): 0,51 & \\
\hline & & & & E. coli (ipm 389): 0,51 & \\
\hline & & & & $P$. aeruginosa (339): 1,02 & \\
\hline & & & & S. mutans (ATCC 10449): 0,25 & \\
\hline & & & & P. gingivalis (ATCC 33277): 0,25 & \\
\hline \multirow[t]{6}{*}{ (+) ampelopsina A } & Flavonóide & Vitis amurensis Rupr. & Difusão em & $\mathrm{CIM}(\mathrm{mg} / \mathrm{mL})$ & Yim et al., 2010 \\
\hline & & & disco & S. mutans: 0,2 & \\
\hline & & & & S. sanguis $>0,4$ & \\
\hline & & & & Halo de inibição (mm) & \\
\hline & & & & S. mutans: NA & \\
\hline & & & & S. sanguis: NA & \\
\hline \multirow[t]{6}{*}{ (+)-ampelopsina F } & Flavonóide & Vitis amurensis Rupr. & Difusão em & $\mathrm{CIM}(\mathrm{mg} / \mathrm{mL})$ & Yim et al., 2010 \\
\hline & & & disco & S. mutans: 0,1 & \\
\hline & & & & S. sanguis $>0,4$ & \\
\hline & & & & Halo de inibição (mm) & \\
\hline & & & & S. mutans $<11,0$ & \\
\hline & & & & S. sanguis: NA & \\
\hline \multirow{5}{*}{$\begin{array}{l}\text { 5,7-dihidroxi-2- } \\
\text { metilcromona 8-C- } \beta \text {-D- } \\
\text { glucopiranosídeo }\end{array}$} & Cumarina & Syzygium & Diluição em & $\mathrm{CIM}(\mathrm{mg} / \mathrm{mL})$ & Cai \& Wu, 1996 \\
\hline & & aromaticum (L.) & caldo & P. gingivalis (ATCC 33277): 0,312 & \\
\hline & & Merr. et Perry & & P. intermedia: 0,156 & \\
\hline & & & & S. mutans Ingbritt $>2,5$ & \\
\hline & & & & A. viscosus (W1053) > 2,5 & \\
\hline \multirow{2}{*}{$\begin{array}{c}\text { 6,8-diisoprenil-5,7,4- } \\
\text { trihidroxi-isoflavona }\end{array}$} & Flavonóide & Glycyrrhiza uralensis & Microdiluição & $\mathrm{CIM}(\mathrm{mg} / \mathrm{mL})$ & He et al., 2006 \\
\hline & & Fisch. ex DC. & & S. mutans (ATCC 25175): 0,002 & \\
\hline \multirow[t]{5}{*}{ (-)-epicatequina } & Flavonóide & Byrsonima & Microdiluição & $\mathrm{CIM}(\mathrm{mg} / \mathrm{mL})$ & Rivero-Cruz et al., \\
\hline & & crassifolia L. & & S. aureus (375): 0,13 & 2009 \\
\hline & & & & S. aureus (ATCC 25923): 0,52 & \\
\hline & & & & B. subtilis (327): 0,52 & \\
\hline & & & & E. coli (ipm 389): 0,52 & \\
\hline \multirow[t]{4}{*}{ (-)-epicatequina } & Flavonóide & & Microdiluição & $\mathrm{CIM}(\mathrm{mg} / \mathrm{mL})$ & Rivero-Cruz et al., \\
\hline & & Byrsonima & & P. aeruginosa (339): 1,24 & 2009 \\
\hline & & crassifolia L. & & S. mutans (ATCC 10449): 0,03 & \\
\hline & & & & P. gingivalis (ATCC 33277): 0,06 & \\
\hline \multirow[t]{2}{*}{ 5-O-metil-glicriol } & Flavonóide & Glycyrrhiza uralensis & Microdiluição & $\mathrm{CIM}(\mathrm{mg} / \mathrm{mL})$ & He et al., 2006 \\
\hline & & Fisch. ex DC. & & S. mutans (ATCC 25175): 0,5 & \\
\hline \multirow[t]{5}{*}{ 7-metil-juglone } & Composto & Diospyros lycioides & Microtitulação & $\mathrm{CIM}(\mathrm{mg} / \mathrm{mL})$ & Cai et al., 2000 \\
\hline & aromático & Desf. & & S. mutans Ingbritt: 0,156 & \\
\hline & policíclico & & & S. sanguis: 0,078 & \\
\hline & & & & P. gingivalis: 0,039 & \\
\hline & & & & P. intermedia: 0,078 & \\
\hline \multirow[t]{6}{*}{ 2-r-viniferina } & Polifenol & Vitis amurensis Rupr. & Difusão em & $\mathrm{CIM}(\mathrm{mg} / \mathrm{mL})$ & Yim et al., 2010 \\
\hline & & & disco & S. mutans: 0,05 & \\
\hline & & & & S. sanguis: 0,20 & \\
\hline & & & & Halo de inibição (mm) & \\
\hline & & & & S. mutans $<11,0$ & \\
\hline & & & & S. sanguis $<11,0$ & \\
\hline
\end{tabular}


TABELA 3. Substâncias isoladas de espécies vegetais com estudos de avaliação da atividade antimicrobiana in vitro sobre patógenos orais, com indicação do microrganismo testado e método

\begin{tabular}{|c|c|c|c|c|c|}
\hline Substância Química & Classe & Espécie Vegetal & Método & Microrganismo/Resultado & Referências \\
\hline \multirow[t]{6}{*}{$\square$-terpineno } & Terpeno & Origanum scabrum & Diluição & $\mathrm{CIM}(\mathrm{mg} / \mathrm{mL})$ & Aligiannis et al., \\
\hline & & Boiss. \& Heldr. & seriada & S. aureus (ATCC 25923): NA & 2001 \\
\hline & & & & S. epidermidis (ATCC 12228): NA & \\
\hline & & & & E. coli (ATCC 25922): NA & \\
\hline & & & & K. pneumoniae (ATCC 13883): NA & \\
\hline & & & & $P$. aeruginosa (ATCC 227853): NA & \\
\hline \multirow[t]{6}{*}{ p-cymeno } & Terpeno & Origanum scabrum & Diluição & $\mathrm{CIM}(\mathrm{mg} / \mathrm{mL})$ & Aligiannis et al., \\
\hline & & Boiss. \& Heldr. & seriada & S. aureus (ATCC 25923): NA & 2001 \\
\hline & & & & S. epidermidis (ATCC 12228): NA & \\
\hline & & & & E. coli (ATCC 25922): NA & \\
\hline & & & & K. pneumoniae (ATCC 13883): NA & \\
\hline & & & & P. aeruginosa (ATCC 227853): NA & \\
\hline \multirow[t]{4}{*}{ Ácido beta } & Ácido fenólico & Humulus lupulus $\mathrm{L}$. & Difusão em & Halo de inibição (mm) & Bhattacharya et \\
\hline & & & disco & S. mutans (ATCC 25175 ): 13,0 & al., 2003 \\
\hline & & & & S. salivarius (ATCC 13419): 15,0 & \\
\hline & & & & S. sanguis (ATCC 10556): 12,0 & \\
\hline \multirow[t]{8}{*}{ Ácido betulínico } & Terpeno & Byrsonima & Microdiluição & $\mathrm{CIM}(\mathrm{mg} / \mathrm{mL})$ & Rivero-Cruz et al., \\
\hline & & crassifolia L. & & S. aureus (375): 1,08 & 2009 \\
\hline & & & & S. aureus (ATCC 25923): 1,08 & \\
\hline & & & & B. subtilis (327): 1,08 & \\
\hline & & & & E. coli (ipm 389): 1,08 & \\
\hline & & & & P. aeruginosa (339): 1,08 & \\
\hline & & & & S. mutans (ATCC 10449): 0,54 & \\
\hline & & & & P. gingivalis (ATCC 33277): 0,54 & \\
\hline \multirow[t]{5}{*}{ Ácido ceanotérico } & Terpeno & Ceanothus americanus & Diluição & $\mathrm{CIM}\left(\mathrm{mg} / \mathrm{mL}^{-1}\right)$ & Li et al., 1997 \\
\hline & & L. & seriada & S. mutans: 0,625 & \\
\hline & & & & A. viscosus: 0,562 & \\
\hline & & & & P. gingivalis: 0,562 & \\
\hline & & & & P. intermedia: 0,406 & \\
\hline \multirow[t]{5}{*}{ Ácido ceanótico } & Terpeno & Ceanothus americanus & Diluição & $\mathrm{CIM}\left(\mathrm{mg} / \mathrm{mL}^{-1}\right)$ & Li et al., 1997 \\
\hline & & L. & seriada & S. mutans: 0,250 & \\
\hline & & & & A. viscosus: 0,042 & \\
\hline & & & & P. gingivalis: 0,062 & \\
\hline & & & & P. intermedia: 0,062 & \\
\hline \multirow[t]{5}{*}{ Ácido elágico } & Ácido fenólico & Syzygium aromaticum & Diluição em & $\mathrm{CIM}(\mathrm{mg} / \mathrm{mL})$ & Cai \& Wu, 1996 \\
\hline & & (L.) Merr. et Perry & caldo & P. gingivalis (ATCC 33277): 1,25 & \\
\hline & & & & P. intermedia: 1,25 & \\
\hline & & & & S. mutans Ingbritt: 1,25 & \\
\hline & & & & A. viscosus (W1053): 1,25 & \\
\hline \multirow[t]{9}{*}{ Ácido gálico } & Ácido fenólico & Byrsonima & Microdiluição & $\mathrm{CIM}(\mathrm{mg} / \mathrm{mL})$ & Rivero-Cruz et al., \\
\hline & & crassifolia L. & & S. aureus (375): 0,25 & 2009 \\
\hline & & & & S. aureus (ATCC 25923): 0,25 & \\
\hline & & & & B. subtilis (327): 0,25 & \\
\hline & & & & E. coli (ipm 389): 0,51 & \\
\hline & & & & P. aeruginosa (339): 1,02 & \\
\hline & & & & S. mutans (ATCC 10449): 0,12 & \\
\hline & & & & P. gingivalis (ATCC 33277): 0,06 & \\
\hline & & & & P. gingivalis (ATCC 33277): 156,0 & \\
\hline \multirow[t]{4}{*}{ Ácido gálico } & Ácido fenólico & Syzygium & Diluição em & $\mathrm{CIM}(\mathrm{mg} / \mathrm{mL})$ & Cai \& Wu, 1996 \\
\hline & & aromaticum (L.) & caldo & P. intermedia: 78,0 & \\
\hline & & Merr. et Perry & & S. mutans Ingbritt $>2500,0$ & \\
\hline & & & & A. viscosus (W1053): 78,0 & \\
\hline
\end{tabular}

continua..

Rev. Bras. PI. Med., Campinas, v.16, n.1, p.135-167, 2014. 
TABELA 3. Substâncias isoladas de espécies vegetais com estudos de avaliação da atividade antimicrobiana in vitro sobre patógenos orais, com indicação do microrganismo testado e método

continuação...

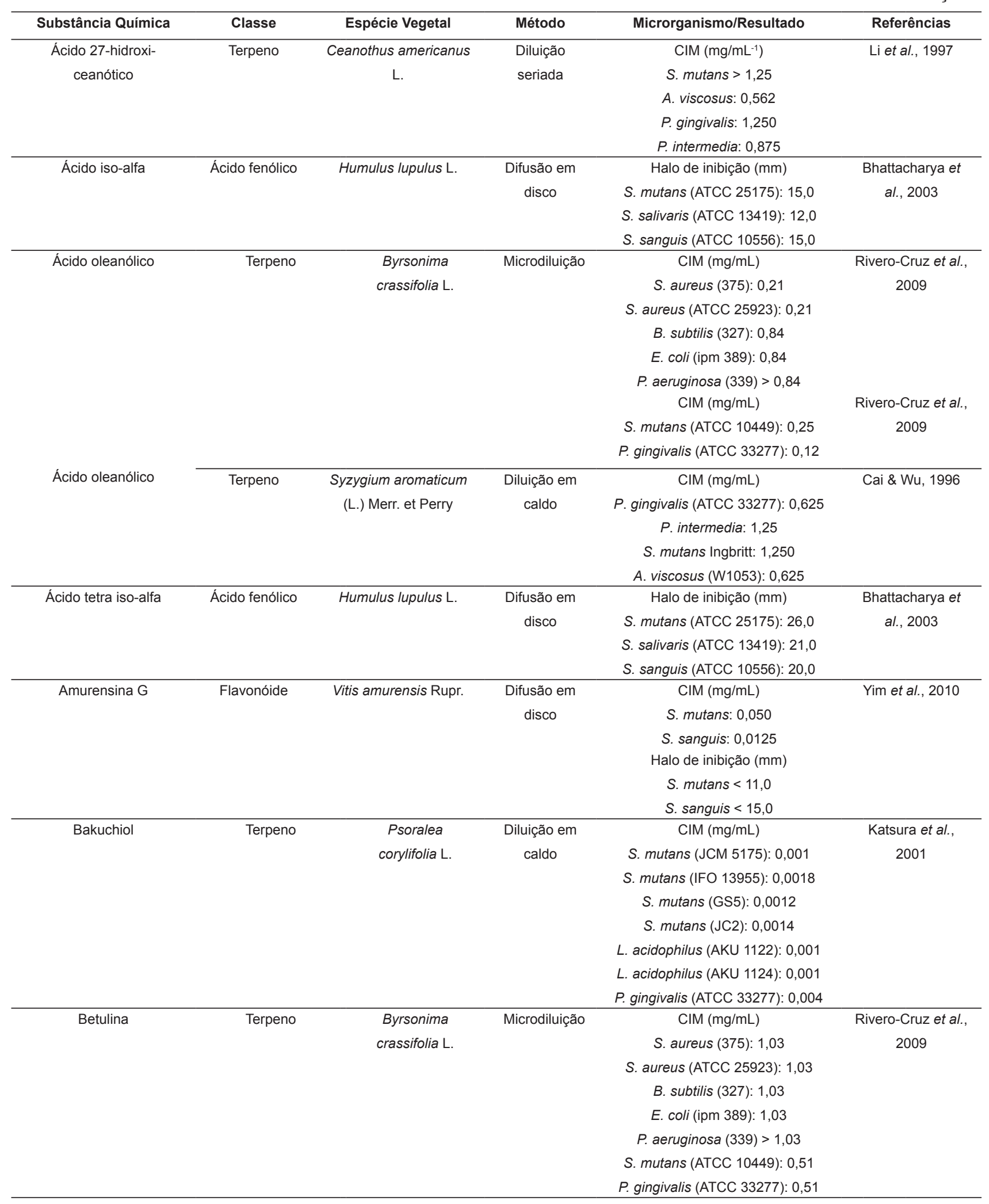


TABELA 3. Substâncias isoladas de espécies vegetais com estudos de avaliação da atividade antimicrobiana in vitro sobre patógenos orais, com indicação do microrganismo testado e método

continuação...

\begin{tabular}{|c|c|c|c|c|c|}
\hline Substância Química & Classe & Espécie Vegetal & Método & Microrganismo/Resultado & Referências \\
\hline \multirow[t]{5}{*}{ Biflorina } & Quinona & Syzygium aromaticum & Diluição em & $\mathrm{CIM}(\mathrm{mg} / \mathrm{mL})$ & Cai \& Wu, 1996 \\
\hline & & (L.) Merr. et Perry & caldo & P. gingivalis (ATCC 33277): 0,625 & \\
\hline & & & & P. intermedia: 0,625 & \\
\hline & & & & S. mutans Ingbritt $>2,5$ & \\
\hline & & & & A. viscosus (W1053) > 2,5 & \\
\hline \multirow[t]{5}{*}{ Canferol } & Flavonóide & Syzygium aromaticum & Diluição em & $\mathrm{CIM}(\mathrm{mg} / \mathrm{mL})$ & Cai \& Wu, 1996 \\
\hline & & (L.) Merr. et Perry & caldo & P. gingivalis (ATCC 33277): 0,02 & \\
\hline & & & & P. intermedia: 0,020 & \\
\hline & & & & S. mutans Ingbritt: 2,5 & \\
\hline & & & & A. viscosus (W1053): 1,25 & \\
\hline \multirow[t]{16}{*}{ Carvacrol } & Terpeno & Lippia sidoides Cham. & Diluição e & Halo de inibição (mm) & Botelho et al., \\
\hline & & & disco difusão & S. mutans (ss-980): 8,0 & 2007 \\
\hline & & & em ágar & S. mitis $(\mathrm{IC}): 13,0$ & \\
\hline & & & & S. salivaris (IC): 7,5 & \\
\hline & & & & S. sanguis (IC): 15,0 & \\
\hline & & & & $\mathrm{CIM}(\mathrm{mg} / \mathrm{mL})$ & \\
\hline & & & & S. mutans: 2,5 & \\
\hline & & & & S. mitis: 2,5 & \\
\hline & & & & S. sanguis: 2,5 & \\
\hline & & & & S. salivaris: 2,5 & \\
\hline & & Origanum scabrum & Diluição & $\mathrm{CIM}(\mathrm{mg} / \mathrm{mL})$ & Aligiannis et al., \\
\hline & & Boiss. \& Heldr. & seriada & S. aureus (ATCC 25923): 0,1 & 2001 \\
\hline & & & & S. epidermidis (ATCC 12228): 0,1 & \\
\hline & & & & E. coli (ATCC 25922): 0,1 & \\
\hline & & & & K. pneumoniae (ATCC 13883): 0,5 & \\
\hline & & & & P. aeruginosa (ATCC 227853): 1,0 & \\
\hline Deidrodiconiferilálcool- & Fenol & $\mathrm{NI}$ & Microdiluição & $\mathrm{CIM}(\mathrm{mg} / \mathrm{mL})$ & Takara et al., 2007 \\
\hline $9-O-\beta-D$ & & & & S. mutans (ATCC 25175) > 4 & \\
\hline glucopiranosídeo & & & & S. sobrinus (ATCC 33478) > 4 & \\
\hline \multirow[t]{5}{*}{ Diospirosídeo A } & Composto & Diospyros lycioides & Microtitulação & $\mathrm{CIM}(\mathrm{mg} / \mathrm{mL})$ & Cai et al., 2000 \\
\hline & aromático & Desf. & & S. mutans Ingbritt: 1,25 & \\
\hline & policíclico & & & S. sanguis: 0,039 & \\
\hline & & & & P. gingivalis: 0,078 & \\
\hline & & & & P. intermedia: 0,039 & \\
\hline \multirow[t]{5}{*}{ Diospirosídeo B } & Composto & Diospyros lycioides & Microtitulação & $\mathrm{CIM}(\mathrm{mg} / \mathrm{mL})$ & Cai et al., 2000 \\
\hline & aromático & Desf. & & S. mutans Ingbritt: 0,625 & \\
\hline & policíclico & & & S. sanguis: 0,039 & \\
\hline & & & & P. gingivalis: 0,078 & \\
\hline & & & & P. intermedia: 0,156 & \\
\hline \multirow[t]{5}{*}{ Diospirosídeo C } & Composto & Diospyros lycioides & Microtitulação & $\mathrm{CIM}(\mathrm{mg} / \mathrm{mL})$ & Cai et al., 2000 \\
\hline & aromático & Desf. & & S. mutans Ingbritt: 0,156 & \\
\hline & policíclico & & & S. sanguis: 0,625 & \\
\hline & & & & P. gingivalis: 0,312 & \\
\hline & & & & P. intermedia: 0,039 & \\
\hline \multirow[t]{5}{*}{ Diospirosídeo D } & Composto & Diospyros lycioides & Microtitulação & $\mathrm{CIM}(\mathrm{mg} / \mathrm{mL})$ & Cai et al., 2000 \\
\hline & aromático & Desf. & & S. mutans Ingbritt: 0,156 & \\
\hline & policíclico & & & S. sanguis: 0,312 & \\
\hline & & & & P. gingivalis: 0,156 & \\
\hline & & & & P. intermedia: 0,156 & \\
\hline
\end{tabular}


TABELA 3. Substâncias isoladas de espécies vegetais com estudos de avaliação da atividade antimicrobiana in vitro sobre patógenos orais, com indicação do microrganismo testado e método

continuação...

\begin{tabular}{|c|c|c|c|c|c|}
\hline Substância Química & Classe & Espécie Vegetal & Método & Microrganismo/Resultado & Referências \\
\hline \multirow[t]{7}{*}{ Casbano } & Terpeno & Croton nepetaefolius & Microdiluição & $\mathrm{CIM}(\mathrm{mg} / \mathrm{mL})$ & Carneiro et al., \\
\hline & & Baill. & & P. fluorescens (ATCC 13525): 0,125 & 2011 \\
\hline & & & & P. aeruginosa (ATCC 1014): 0,25 & \\
\hline & & & & P. aeruginosa (CGCT 111): 0,5 & \\
\hline & & & & E. coli (K12): 0,5 & \\
\hline & & & & S. epidermidis (CECT 4183): 0,5 & \\
\hline & & & & S. aureus (JKD 6008): 0,25 & \\
\hline \multirow[t]{2}{*}{ Gancaonina G } & Flavonóide & Glycyrrhiza uralensis & Microdiluição & $\mathrm{CIM}(\mathrm{mg} / \mathrm{mL})$ & He et al., 2006 \\
\hline & & Fisch. ex DC. & & S. mutans (ATCC 25175): 0,125 & \\
\hline \multirow[t]{2}{*}{ Glicirrizol A } & Flavonóide & Glycyrrhiza uralensis & Microdiluição & $\mathrm{CIM}(\mathrm{mg} / \mathrm{mL})$ & He et al., 2006 \\
\hline & & Fisch. ex DC. & & S. mutans (ATCC 25175): 0,001 & \\
\hline \multirow[t]{2}{*}{ Glicirrizol B } & Flavonóide & Glycyrrhiza uralensis & Microdiluição & $\mathrm{CIM}(\mathrm{mg} / \mathrm{mL})$ & He et al., 2006 \\
\hline & & Fisch. ex DC. & & S. mutans (ATCC 25175): 0,032 & \\
\hline \multirow[t]{3}{*}{ Guaijaverina } & Flavonóide & Psidium guajava L. & Difusão em & $\mathrm{CIM}\left(\mathrm{mg} / \mathrm{mL}^{-1}\right)$ & Prabu et al., 2006 \\
\hline & & & ágar & S. mutans (MTCC 1943): 4,0 & \\
\hline & & & & S. mutans (IC): 2,0 & \\
\hline \multirow[t]{8}{*}{ Hidroxi-chavicol } & Fenol & Piper betle L. & Diluição em & $\mathrm{CIM}(\mathrm{mg} / \mathrm{mL})$ & Sharma et al., \\
\hline & & & caldo & S. mutans (ATCC 25175): 0,25-0,5 & 2009 \\
\hline & & & & S. sanguis (ATCC 10556): 0,125-0,5 & \\
\hline & & & & A. viscosus (ATCC 15987): 0,25-0,5 & Sharma et al., \\
\hline & & & & P. intermedia (ATCC 25611): 0,125-0,5 & 2009 \\
\hline & & & & P. gingivalis (ATCC 33277 ): $0,062-0,25$ & \\
\hline & & & & F. nucleatum (ATCC 10953): 0,125- & \\
\hline & & & & 0,25 & \\
\hline \multirow[t]{2}{*}{ Isoglicirol } & Flavonóide & Glycyrrhiza uralensis & Microdiluição & $\mathrm{CIM}(\mathrm{mg} / \mathrm{mL})$ & He et al., 2006 \\
\hline & & Fisch. ex DC. & & S. mutans (ATCC 25175): 0,5 & \\
\hline Iso-orientina & Fenol & $\mathrm{NI}$ & Microdiluição & $\mathrm{CIM}(\mathrm{mg} / \mathrm{mL})$ & Takara et al., 2007 \\
\hline \multirow[t]{2}{*}{ 7,3-O-dimetil-éter } & & & & S. mutans (ATCC 25175): 4,0 & \\
\hline & & & & S. sobrinus (ATCC 33478 ): 4,0 & \\
\hline \multirow[t]{5}{*}{ Juglona } & Composto & Diospyros lycioides & Microtitulação & $\mathrm{CIM}(\mathrm{mg} / \mathrm{mL})$ & Cai et al., 2000 \\
\hline & aromático & Desf. & & S. mutans Ingbritt: 0,078 & \\
\hline & policíclico & & & S. sanguis: 0,039 & \\
\hline & & & & P. gingivalis: 0,039 & \\
\hline & & & & P. intermedia: 0,019 & \\
\hline \multirow[t]{8}{*}{ Kuwanona G } & Flavonóide & Morus alba L. & Ensaio de & $\mathrm{CIM}(\mathrm{mg} / \mathrm{mL})$ & Park \\
\hline & & & difusão & S. mutans (ATCC 25175): 0,008 & et al., \\
\hline & & & & S. sanguis (ATCC 35105): 0,008 & 2003 \\
\hline & & & & S. sobrinus (ATCC 27351): 0,008 & \\
\hline & & & & L. acidophilus (ATCC 4356) $>1,0$ & \\
\hline & & & & L. casei (ATCC 4646) > 1,0 & \\
\hline & & & & P. gingivalis (W50): 0,008 & \\
\hline & & & & A. actinomycetemcomitans (ATCC 3338 & 84): 1,0 \\
\hline \multirow[t]{6}{*}{ Linalol } & Terpeno & Croton cajucara Benth & Diluição & $\mathrm{CIM}(\mathrm{mg} / \mathrm{mL})$ & Alviano et al., 2005 \\
\hline & & & & L. casei (ATCC 4646): 0,022 & \\
\hline & & & & S. aureus (ATCC 49456): 0,033 & \\
\hline & & & & S. sobrinus (ATCC 27609): 0,013 & \\
\hline & & & & P. gingivalis (ATCC 43146): 0,031 & \\
\hline & & & & S. mutans (ATCC 25175): 0,040 & \\
\hline
\end{tabular}


TABELA 3. Substâncias isoladas de espécies vegetais com estudos de avaliação da atividade antimicrobiana in vitro sobre patógenos orais, com indicação do microrganismo testado e método

continuação..

\begin{tabular}{|c|c|c|c|c|c|}
\hline Substância Química & Classe & Espécie Vegetal & Método & Microrganismo/Resultado & Referências \\
\hline \multirow[t]{5}{*}{ Maesopsina } & Flavonóide & Ceanothus americanus & Diluição & $\mathrm{CIM}\left(\mathrm{mg} / \mathrm{mL}^{-1}\right)$ & Li et al., 1997 \\
\hline & & L. & seriada & S. mutans $>2,5$ & \\
\hline & & & & A. viscosus $>2,5$ & \\
\hline & & & & P. gingivalis: 2,5 & \\
\hline & & & & P. intermedia: 2,5 & \\
\hline Maesopsina-6-O- & Flavonóide & Ceanothus americanus & Diluição & $\mathrm{CIM}\left(\mathrm{mg} / \mathrm{mL}^{-1}\right)$ & Li et al., 1997 \\
\hline \multirow[t]{4}{*}{ glucosideo } & & L. & seriada & S. mutans: 2,5 & \\
\hline & & & & A. viscosus: $>2,5$ & \\
\hline & & & & P. gingivalis: 1,25 & \\
\hline & & & & P. intermedia: 1,25 & \\
\hline \multirow[t]{2}{*}{ Mentol } & Terpeno & Mentha longifolia L. & Disco difusão & Halo de inibição $(\mathrm{mm})$ & Al-Bayati, 2009 \\
\hline & & & em ágar & S. mutans: 25,3 & \\
\hline \multirow[t]{5}{*}{ Miricetina } & Flavonóide & Syzygium aromaticum & Diluição em & $\mathrm{CIM}(\mathrm{mg} / \mathrm{mL})$ & Cai \& Wu, 1996 \\
\hline & & (L.) Merr. et Perry & caldo & P. gingivalis (ATCC 33277): 0,02 & \\
\hline & & & & P. intermedia: 0,02 & \\
\hline & & & & S. mutans Ingbritt: 2,5 & \\
\hline & & & & A. viscosus (W1053): 1,25 & \\
\hline \multirow[t]{4}{*}{ Panduratina $\mathrm{A}$} & Flavonóide & Kaempferia pandurata & Microdiluição & $\mathrm{CIM}(\mathrm{mg} / \mathrm{mL})$ & Yanti et al., 2009 \\
\hline & & Roxb. & & S. mutans (ATCC 25175): 0,001 & \\
\hline & & & & S. sanguis (ATCC 10556): 0,001 & \\
\hline & & & & A. viscosus (KCCM 12074): 0,001 & \\
\hline \multirow[t]{6}{*}{ Piceatannol } & Fenol & Vitis amurensis Rupr. & Difusão em & $\mathrm{CIM}(\mathrm{mg} / \mathrm{mL})$ & Yim et al., 2010 \\
\hline & & & disco & S. mutans: 0,050 & \\
\hline & & & & S. sanguis: 0,050 & \\
\hline & & & & Halo de inibição $(\mathrm{mm})$ & \\
\hline & & & & S. mutans $<15,0$ & \\
\hline & & & & S. sanguis $<15,0$ & \\
\hline Piceatannol-3-O-D- & Fenol & Vitis amurensis & Difusão em & $\mathrm{CIM}(\mathrm{mg} / \mathrm{mL})$ & Yim et al., 2010 \\
\hline \multirow[t]{5}{*}{ glicosídeo } & & Rupr. & disco & S. mutans: NA & \\
\hline & & & & S. sanguis: NA & \\
\hline & & & & Halo de inibição $(\mathrm{mm})$ & \\
\hline & & & & S. mutans: NA & \\
\hline & & & & S. sanguis: NA & \\
\hline \multirow[t]{7}{*}{ Quercetina } & Flavonóide & Byrsonima & Microdiluição & $\mathrm{CIM}(\mathrm{mg} / \mathrm{mL})$ & Rivero-Cruz et al., \\
\hline & & crassifolia L. & & S. aureus (ATCC 25923): 0,50 & 2009 \\
\hline & & & & B. subtilis (327): 0,5 & \\
\hline & & & & E. coli (ipm 389): 1,01 & \\
\hline & & & & $P$. aeruginosa $(339)>1,01$ & \\
\hline & & & & S. mutans (ATCC 10449): 0,51 & \\
\hline & & & & P. gingivalis (ATCC 33277): 0,25 & \\
\hline \multirow[t]{5}{*}{ Raminocitrina } & Flavonóide & Syzygium aromaticum & Diluição em & $\mathrm{CIM}(\mathrm{mg} / \mathrm{mL})$ & Cai \& Wu, 1996 \\
\hline & & (L.) Merr. et Perry & caldo & P. gingivalis (ATCC 33277): 0,625 & \\
\hline & & & & P. intermedia: 0,625 & \\
\hline & & & & S. mutans Ingbritt: 1,25 & \\
\hline & & & & A. viscosus (W1053): 1,25 & \\
\hline
\end{tabular}


TABELA 3. Substâncias isoladas de espécies vegetais com estudos de avaliação da atividade antimicrobiana in vitro sobre patógenos orais, com indicação do microrganismo testado e método

continuação...

\begin{tabular}{|c|c|c|c|c|c|}
\hline Substância Química & Classe & Espécie Vegetal & Método & Microrganismo/Resultado & Referências \\
\hline \multirow[t]{10}{*}{ Timol } & Terpeno & Lippia sidoides Cham. & Diluição e & Halo de inibição $(\mathrm{mm})$ & Botelho et al., \\
\hline & & & disco difusão & S. mutans (ss-980): 7,8 & 2007 \\
\hline & & & em ágar & S. mitis (IC): 15,0 & \\
\hline & & & & S. salivarius (IC): 7,7 & \\
\hline & & & & S. sanguis (IC): 16,0 & \\
\hline & & & & $\mathrm{CIM}(\mathrm{mg} / \mathrm{mL})$ & \\
\hline & & & & S. mutans (ss-980): 5,0 & \\
\hline & & & & S. mitis (IC): 5,0 & \\
\hline & & & & S. sanguis (IC): 5,0 & \\
\hline & & & & S. salivaris (IC): 5,0 & \\
\hline \multirow[t]{6}{*}{ Trans- $\varepsilon$-viniferina } & Fenol & Vitis amurensis Rupr. & Difusão em & $\mathrm{CIM}(\mathrm{mg} / \mathrm{mL})$ & Yim et al., 2010 \\
\hline & & & disco & S. mutans: 0,025 & \\
\hline & & & & S. sanguis: 0,0125 & \\
\hline & & & & Halo de inibição $(\mathrm{mm})$ & \\
\hline & & & & S. mutans $<15,0$ & \\
\hline & & & & S. sanguis: 20,0 & \\
\hline \multirow[t]{6}{*}{ Trans-resveratrol } & Flavonóide & Vitis amurensis Rupr. & Difusão em & $\mathrm{CIM}(\mathrm{mg} / \mathrm{mL})$ & Yim et al., 2010 \\
\hline & & & disco & S. mutans: 0,050 & \\
\hline & & & & S. sanguis: 0,025 & \\
\hline & & & & Halo de inibição $(\mathrm{mm})$ & \\
\hline & & & & S. mutans $<15,0$ & \\
\hline & & & & S. sanguis $<11,0$ & \\
\hline Trans-resveratrol-3-O-D- & Flavonóide & Vitis amurensis Rupr. & Difusão em & $\mathrm{CIM}(\mathrm{mg} / \mathrm{mL})$ & Yim et al., 2010 \\
\hline \multirow[t]{5}{*}{ glucosídeo } & & & disco & S. mutans: NA & \\
\hline & & & & S. sanguis: NA & \\
\hline & & & & Halo de inibição $(\mathrm{mm})$ & \\
\hline & & & & S. mutans NA & \\
\hline & & & & S. sanguis: NA & \\
\hline \multirow[t]{4}{*}{ Xantohumol } & Flavonóide & Humulus lupulus $\mathrm{L}$. & Difusão em & Halo de inibição $(\mathrm{mm})$ & Bhattacharya et \\
\hline & & & disco & S. mutans (ATCC 25175): 10,0 & al., 2003 \\
\hline & & & & S. salivaris (ATCC 13419): 12,0 & \\
\hline & & & & S. sanguis (ATCC 10556): 13,0 & \\
\hline \multirow[t]{2}{*}{ Xantorrizol } & Terpeno & Curcuma xanthorrhiza & Cristal de & Concentração de 5 umol/ L-1: $100 \%$ & Rukayadi \& \\
\hline & & Roxb. & violeta & de inibição do biofilme & Hwang, 2006 \\
\hline
\end{tabular}

CIM: Concentração Inibitória Mínima; IC: Isolado Clínico; NA: Não Ativo; NI: Não Informado.

continuidade dos estudos com as espécies vegetais com potencial atividade antimicrobiana contra patógenos orais, visando a busca de novas terapias complementares na odontologia.

\section{REFERÊNCIA}

ADEJUMOBI, J.A.; OGUNDIYA, M.O.; KOLAPO, A.L.E.; OKUNADE, M. Phytochemical composition and in vitro antimicrobial activity of Anogeissus leiocarpus on some common oral pathogens. Journal of Medicinal Plants Research, v. 2, p. 193-196, 2008.

AGRA, M.F.; BARACHO, G.S.; BASÍLIO, I.J.D.; NURIT, K.; COELHO, V.P.; BARBOSA, D.A. Sinopse da flora medicinal do cariri paraibano. Oecologia Brasiliensis, v.
11, p. 323-330, 2007a.

AGRA, M.F.; FREITAS, P.F.; BARBOSA, F.J.M. Synopsis of the plants known as medicinal and poisonous in Northeast of Brazil. Revista Brasileira de Farmacognosia, v. 17, p. 114-140, 2007b.

AL-BAYATI, F.A. Isolation and identification of antimicrobial compound from Mentha longifolia L. leaves grown wild in Iraq. Annals of Clinical Microbiology and Antimicrobials, v. 8, p. 2-6, 2009.

ALBUQUERQUE, A.C.L.; PEREIRA, M.S.V.; PEREIRA, J.V.C.; MARIA, R.M.; HIGINO, J.S. Efeito antimicrobiano do extrato da Lippia sidoides Cham. sobre microrganismos cariogênicos. Arquivos de Odontologia, v. 44, p. 05-10, 2008.

ALBUQUERQUE, A.C.L.; PEREIRA, M.S.V.; PEREIRA, J.V.; PEREIRA, L.F.; SILVA, D.F.; MACEDO, C.M.R.; HIGINO, J.S. Antiadherent effect of the extract of the 
Matricaria recutita Linn. on microrganisms of dental biofilm. Revista de Odontologia da UNESP v. 39, p. 21-25, 2010.

ALBUQUERQUE, U.P. Re-examining hypotheses concerning the use and knowledge of medicinal plants: study in Caatinga vegetation of NE Brazil. Journal of Ethnobiology and Ethnomedicine, v. 2, p.1-10, 2006. ALIGIANNIS, N.; KALPOUTZAKIS, E.; MITAKU, S.; CHINOU, I.B. Composition and antimicrobial activity of the essential oils of two Origanum species. Journal of Agricultural and Food Chemistry, v. 49, p. 41684170, 2001.

ALVES, E.O.J.H.; SOARES, T.S.; VIEIRA, M.C.; SILVA, C.B. Levantamento etnobotânico e caracterização de plantas medicinais em fragmentos florestais de Dourados - MS. Ciência e Agrotecnologia, v. 32, p. 651-658, 2008.

ALVES, P.M.; QUEIROZ, L.M.G.; PEREIRA, J.V.; PEREIRA, M.S.V. Atividade antimicrobiana, antiaderente e antifúngica in vitro de plantas medicinais brasileiras sobre microrganismos do biofilme dental e cepas do gênero Candida. Revista da Sociedade Brasileira de Medicina Tropical, v. 42, 222-224, 2009.

ALVIANO, W.S.; ALVIANO, D.S.; DINIZ, C.G.; ANTONIOLLI, A.R.; ALVIANO, C.S.; FARIAS, L.M.; CARVALHO, M.A.; SOUZA, M.M.; BOLOGNESE, A.M. In vitro antioxidant potential of medicinal plant extracts and their activities against oral bacteria based on Brazilian folk medicine. Archives of Oral Biology, v. 53, p. 545-552, 2008.

ALVIANO, W.S.; MENDONÇA-FILHO, R.R.; ALVIANO, D.S.; BIZZO, H.R.; PADRÓN, T.S.; RODRIGUES, M.L.; BOLOGNESE, A.M.; ALVIANO, C.S.; SOUZA, M.M.G. Antimicrobial activity of Croton cajucara Benth linaloolrich essential oil on artificial biofilms and planktonic microorganisms. Oral Microbiology and Immunology, v.20, p. 101-105, 2005.

AMARAL, F.M.M. Potencial giardicida de espécies vegetais: aspectos da etnofarmacologia e bioprospecção. Paraíba. 346p. Tese de Doutorado em Produtos Naturais e Sintéticos Bioativos - Universidade Federal da Paraíba, 2007.

ANEJA, K.R.; JOSHI, R. Evaluation of antimicrobial properties of fruit extracts of Terminalia chebula against dental caries pathogens. Jundishapur Journal of Microbiology, v. 2, p. 105-111, 2009.

ARAÚJO, C.R.F.; PEREIRA, J.V.; PEREIRA, M.S.V.; ALVES, P.M.; HIGINO, J.S.; MARTINS, A.B. Concentração Mínima Bactericida do extrato do cajueiro sobre bactérias do biofilme dental. Pesquisa Brasileira de Odontopediatria Clínica integrada, v. 9, p. 187-191, 2009.

ARAÚJO, J.N.; SAKAMOTO, K.S.; BUTEL, P.S.; SANTOS, R.F.; VIEIRA, S.R.; MELO, S. Um estudo das causas e consequências da cárie dentária em crianças de 6 a 12 anos moradoras do bairro Itaúna II no município de Parintins/AM. Anais: 62 ${ }^{\mathrm{a}}$ Reunião Anual da SBPC, Natal, Brasil, 2010.

BABPOUR, E.; ANGAJI, S.A.; ANGAJI, S.M. Antimicrobial effects of four medicinal plants on dental plaque. Journal of Medicinal Plants Research, v. 3, p. 132-137, 2009.

BAKRI, I.M.; DOUGLAS, C.W. Inhibitory effect of garlic extract on oral bacteria. Archives of Oral Biology, v.
50, p. 645-51, 2005.

BAN, S.H.; KWON, Y.R.; PANDIT, S.; LEE, Y.S.; YI, H.K.; JEON, J.G. Effects of a bio-assay guided fraction from Polygonum cuspidatum root on the viability, acid production and glucosyltranferase of mutans Streptococci. Fitoterapia v. 81, p. 30-34, 2010.

BARRETO, L.S. Tipos polínicos dos visitantes florais do umbuzeiro (Spondias tuberosa, Anacardiaceae), no território indígena Pankararé, Raso da Catarina, Bahia, Brasil. Revista Virtual, v.2, p. 80-85, 2006.

BARROS, F.M.C.; PEREIRA, K.N.; ZANETTI, G.D.; HEINZMANN, B.M. Plantas de uso medicinal no município de São Luiz Gonzaga, RS, Brasil. Latin American Journal of Pharmacy, v. 26, p. 652-62, 2007.

BASTOS, J.L.D.; GIGANTE, D.P.; PERES, K.G.; NEDEL, F.B. Determinação social da odontalgia em estudos epidemiológicos: revisão teórica e proposta de um modelo conceitual. Ciência e Saúde Coletiva, v. 12, p. 1611-1621, 2007.

BEYRA, A.; LEÓN, M.C.; IGLESIAS, E.; FERRÁNDIZ, D.; HERRERA, R.; VOLPATO, G.; GODÍNEZ, D.; GUIMARAIS, M.; ALVAREZ, R. Estudios etnobotánicos sobre plantas medicinales en la provincia de Camagüey (Cuba). Anales Jardin Botanico de Madrid, v. 2, p. 185-203, 2004.

BHATTACHARYA, S.; VIRANI, S.; ZAVRO, M.; HAAS, G.J. Inhibition of Streptococcus mutans and other oral Streptococci by hop (Humulus lupulus L.) constituints. Economic Botany, v. 57, p. 118-125, 2003.

BORBA, A.M.; MACEDO, M. Plantas medicinais usadas para a saúde bucal pela comunidade do bairro Santa Cruz, Chapada dos Guimarães, MT, Brasil. Acta Botanica Brasilica, v. 20, p. 771-782, 2006.

BOTELHO, M.A.; NOGUEIRA, N.A.; BASTOS, G.M.; FONSECA, S.G.; LEMOS, T.L.; MATOS, F.J.; MONTENEGRO, D.; HELBACHUKE, J.; RAO, V.S.; BRITO, G.A. Antimicrobial activity of the essential oil from Lippia sidoides, carvacrol and thymol against oral pathogens. Brazilian Journal of Medical and Biological Research, v. 40, p. 349-356, 2007.

CAI, L.; WEI, G.X.; VAN DER BIJL, P. Namibian chewing stick, Diospyros lycioides, contains antibacterial compounds against oral pathogens. Journal of Agricultural and Food Chemistry, v. 48, p. 909-914. 2000.

CAI, L.; WU, C.D. Compounds from Syzygium aromaticum possessing growth inhibitory activity against oral pathogens. Journal of Natural Products, v. 59: p. 987-990, 1996.

CARNEIRO, A.L.; TEIXEIRA, M.F.; OLIVEIRA, V.M.; FERNANDES, O.C.; CAUPER, G.S.;POHLIT, A.M. Screening of Amazonian plants from the Adolpho Ducke forest reserve, Manaus, state of Amazonas, Brazil, for antimicrobial activity. Memórias do Instituto Oswaldo Cruz, v. 103, p. 31-38, 2008.

CARNEIRO, V.A.; SANTOS, H.S.; ARRUDA, F.V.S.; BANDEIRA, P.N.; ALBUQUERQUE, M.R.J.R.; PEREIRA, M.O.; HENRIQUES, M.; CAVADA, B.S.; TEIXEIRA, E.H. Casbane diterpene as a promising natural antimicrobial agent against biofilm-associated infections. Molecules, v.16, p. 190-201, 2011.

CARVALHO, A.M.; MARTINS, M.E.; MOREIRA, A.F. Flora aromática e medicinal do nordeste português: espécies,

Rev. Bras. PI. Med., Campinas, v.16, n.1, p.135-167, 2014. 
usos e saberes da Terra-Fria Transmontana. II Colóquio Nacional de Plantas Aromáticas e Medicinais. Portugal, 2007.

CARVALHO, C.M.; MACEDO, C.M.R.; PEREIRA, M.S.V.; HIGINO, J.S.; CARVALHO, L.F.P.C.; COSTA, L.J. Efeito antimicrobiano in vitro do extrato de jabuticaba [Myrciaria cauliflora (Mart.) O.Berg.] sobre Streptococcus da cavidade oral. Revista Brasileira de Plantas Medicinais, v. 11, p. 79-83, 2009.

CASTELLUCCI, S.; LIMA, M.I.S.; NORDI, N.; MARQUES, J.G.W. Plantas medicinais relatadas pela comunidade residente na Estação Ecológica de Jataí, município de Luís Antônio - SP: uma abordagem etnobotânica. Revista Brasileira de Plantas Medicinais, v. 3, 5160, 2000.

CCAHUANA-VASQUEZ, R.A.; SANTOS, S.S.F.; KOGAITO, C.Y.; JORGE, A.O.C. Antimicrobial activity of Uncaria tomentosa against oral human pathogens. Brazilian Oral Research, v. 21, p. 46-50, 2007.

CHUNG, J.Y.; CHOO, J.H.; LEE, M.H.; HWANG, J.K. Anticariogenic activity of macelignan isolated from Myristica fragrans (nutmeg) against Streptococcus mutans. Phytomedicine, v.13, p. 261-266, 2006.

COLVARD, M.D.; CORDELL, G.A.; VILLALOBOS, R.; SANCHO, G. Survey of medical ethnobotanicals for dental and oral medicine conditions and pathologies. Journal of Ethnopharmacology, v. 107, p. 134-142, 2006.

ELISABETSKY, E. Etnofarmacologia como ferramenta na busca de substâncias ativas. In: SIMÕES COM, SCHENKEL EP, GOSMANN G, MELLO JCP, MENTZ LA, PETROVICK PR. Farmacognosia: da planta ao medicamento, 5. ed. Porto Alegre/Florianópolis: UFSC, 2004.

FANI, M.M.; KOHANTEB, J.; DAVAGHI, M. Inhibitory activity of garlic (Allium sativum) extract on multidrugresistant Streptococcus mutans. Journal of Indian Society of Pedodontics and Preventive Dentistry, v. 25, p. 164-168, 2007.

FEJERSKOV, O.; KIDD, E. Cárie dentária: a doença e seu tratamento clínico. São Paulo: Santos, 2007.

FERRONATTO, R.; MARCHESAN, E.D.; BENDNARSKI, F.; RIBAS, T.T.Z.; ONOFRE, S.B. Efeitos do óleo essencial produzido por Baccharis dracunculifolia D.C. (Compositae) sobre bactérias cariogênicas. Arquivos de Ciências da Saúde da UNIPAR, v. 11, p. 15-18, 2007.

FREIRES, I.A.; ALVES, L.A.; JOVITO, V.C.; ALMEIDA, L.F.D.; CASTRO, R.D.; PADILHA, W.W.N. Atividades antibacteriana e antiaderente in vitro de tinturas de Schinus terebinthinfolius (aroeira) e Solidago microglossa (arnica) frente a bactérias formadoras do biofilme dentário. Odontologia Clínico-científica, v. 9, p. 139-143, 2010.

FURIGA, A.; LONVAUD-FUNEL, A.; BADET, C. In vitro study of antioxidant capacity and antibacterial activity on oral anaerobes of a grape seed extract. Food Chemistry, v. 113, p. 1037-1040, 2009.

GAZZANEO, L.R.S.; LUCENA, R.F.P.; ALBUQUERQUE, U.P. Knowledge and use of medicinal plants by local specialists in an region of Atlantic Forest in the state of Pernambuco (Northeastern Brazil). Journal of
Ethnobiology and Ethnomedicine, v. 1, p. 2-8, 2005. GILANI, A.H.; RAHMAN, A. Trends in ethnopharmacology. Journal of Ethnopharmacology, v. 100, p. 43-49, 2005.

GIRÃO, V.C.; PINHEIRO, D.C.N.; MORAIS, S.M.; SEQUEIRA, J.L.; GIOSO, M.A. A clinical trial of the effect of a mouth-rinse prepared with Lippia sidoides Cham essential oil in dogs with mild gingival disease. Preventive Veterinary Medicine, v. 59, p. 95-102, 2003.

GOMES, E.C.S. et al.. Plantas da Caatinga de uso terapêutico: Levantamento Etnobotânico. Engenharia Ambiental: Pesquisa e Tecnologia, vol. 5, $\mathrm{n}^{\circ} 2$, p. 74-85, 2008.

GONÇALVES, M.I.A.; MARTINS, D.T.O. Plantas medicinais usadas pela população do município de Santo Antônio de Leverger, MT, Brasil. Revista Brasileira de Farmacognosia, v. 79, p. 56-61, 1998.

GUEDES, R.C.M.; NOGUEIRA, N.G.P.; ALMEIDA, A.M.F.; SOUZA, C.R.F.; OLIVEIRA, W.P. Atividade antimicrobiana de extratos brutos de Petiveria alliacea L. Latin American Journal of Pharmacy, v.28, p. 520-524, 2009.

GURIB-FAKIM, A. Medicinal plants: traditions of yesterday and drugs of tomorrow. Molecular Aspects of Medicine, v. 27, p. 1-93, 2006.

HEBBAR, S.S.; HARSHA, V.H.; SHRIPATHI, V.; HEGDE, G.R. Ethnomedicine of Dharwad district in Karnataka, India - plants used in oral health care. Journal of Ethnopharmacology, v. 94, p. 261-266, 2004.

HE, J.; CHEN, L.; HEBER, D.; SHI, W.; YI, Q. Antibacterial compounds from Glycyrrhiza uralensis. Journal of Natural Products, v. 69, p. 121-124, 2006.

HOLETZ, F.B.; PESSINI, G.L.; SANCHES, N.R.; CORTEZ, D.A.; NAKAMURA, C.V.; FILHO, B.P. Screening of some plants used in the Brazilian folk medicine for the treatment of infectious diseases. Memórias do Instituto Oswaldo Cruz, v. 97, p. 1027-1031, 2002.

IAUK, L.; LO BUE, A.M.; MILAZZO, I.; RAPISARDA, A.; BLANDINO, G. Antibacterial activity of medicinal plant extracts against periodontopathic bacteria. Phytotherapy Research, v. 17, p. 599-604, 2002.

JEONG, M.R.; KIM, H.Y., CHA, J.D. Antimicrobial activity of methanol extract from Ficus carica leaves against oral bacteria. Journal of Bacteriology and Virology, v. 39, p. 97-102, 2009.

JUNG, E.K. Chemical composition and antimicrobial activity of the essential oil of Chrysanthemum indicum against oral bacteria. Journal of Bacteriology and Virology, v.39, p. 61-69. 2009.

KATSURA, H.; TSUKIYAMA, R.I.; SUZUKI, A.; KOBAYASHI, M. In vitro antimicrobial activities of bakuchiol against oral microorganisms. Antimicrobial Agents and Chemotherapy, v. 45, p. 3009-3013, 2001.

KOO, H.; GOMES, B.P.F.A.; ROSALEN, P.L.; AMBROSANO, G.M.B.; PARK, Y.K.; CURY, J.A. In vitro antimicrobial activity of propolis and Arnica montana against oral pathogens. Archives of Oral Biology, v. 45, p. 141-148, 2000.

KUSPRADINI, H.; MITSUNAGA, T.; OHASHI, H. Antimicrobial activity against Streptococcus sobrinus and glucosyltransferase inhibitory activity of taxifolin and some flavanonol rhamnosides from kempas (Koompassia malaccensis) extracts. Journal of Wood 
Science, v. 55, p. 308-313, 2009.

LANDUCCI, L.F.; OLIVEIRA, L.D.; BRANDÃO, E.H.S.; KOGA-ITO, C.Y.; JARDIM JÚNIOR, E.G.; JORGE, A.O.C. Efeitos de Coffea arabica sobre a aderência de Streptococcus mutans à superfície de vidro. Ciência Odontológica Brasileira, v.6, p. 58-64, 2003.

LAPA, A.J.; SOUCCAR, C.; LANDMAN, M.T.R.L.; LIMA, T.C.M. Farmacologia e Toxicologia de produtos naturais. In: Simões COM, Schenkel EP, Gosmann G, Mello JCP, Mentz LA, Petrovick PR. Farmacognosia: da planta ao medicamento. 5. ed. Porto Alegre/Florianópolis: UFSC, 2004.

LEITES, A.C.B.R.; PINTO, M.B.; SOUSA, E.R.S. Aspectos microbiológicos da cárie dental. Salusvita, v. 25, p. 239- 252, 2006.

LIMA JÚNIOR, J.F.; DIMENSTEIN, M. A fitoterapia na saúde pública em Natal/RN: visão do odontólogo. Saúde Revista, v. 8, p. 37-44, 2006.

LIMA JÚNIOR, J.F.; VIEIRA. L.B.; LEITE, M.J.V.F.; LIMA, K.C.O. Uso de fitoterápicos e a saúde bucal. Saúde Revista, v. 7, p. 11-17, 2005.

LI, X.C.; CAI, L.; WU, C.D. Antimicrobial compounds from Ceanothus americanus against oral pathogens. Phytochemstry, v. 46, p. 97-102, 1997.

LORENZI, H. Botânica sistemática: Guia ilustrado para identificação das famílias de fanerógamas nativas e exóticas no Brasil. Nova Odessa-SP: Instituto Plantarum, 2005.

MACÊDO-COSTA, M.R.; PEREIRA, M.S.V.; PEREIRA, L.F.; PEREIRA, A.V.; RODRIGUES, O.G. Atividade antimicrobiana e antiaderente do extrato da Mimosa tenuiflora (Willd). Poir. sobre microrganismos do biofilme dentário. Pesquisa Brasileira em Odontopediatria e Clínica Integrada, v. 9, p. 161-165, 2009.

MARWAT, S.K.; KHAN, M.A.; REHMAN, F.; AHMAD, M.Z.M.; SULTANA, S. Salvadora persica, Tamarix aphylla and Zizyphus mauritiana - three woody plant species mentioned in holy Quran and Ahadith and their ethnobotanical uses in North Western part (D.I. Khan) of Pakistan. Pakistan Journal of Nutrition, v. 8, p. 542-547, 2009.

MEDEIROS, M.F.T.; FONSECA, V.S.; ANDREATA, R.H.P. Plantas medicinais e seus usos pelos sitiantes da Reserva Rio das Pedras, Mangaratiba, RJ, Brasil. Acta Botanica Brasilica, v. 18, p. 391-399, 2004.

MELO, A.F.M.; SANTOS, E.J.V.; SOUZA, L.F.C.; CARVALHO, A.A.T.; PEREIRA, M.S.V.; HIGINO, J.S. Atividade antimicrobiana in vitro do extrato de Anacardium occidentale L. sobre espécies de Streptococcus. Revista Brasileira de Farmacognosia, v. 16, p. 202-205, 2006.

MENEZES, M.C.; SOUZA, M.M.S.; BOTELHO, R.P. Avaliação in vitro da atividade antimicrobiana de extratos de plantas brasileiras sobre bactérias isoladas da cavidade oral de cães. Revista Universidade Rural Série Ciências da Vida, v. 24, p. 141-144, 2004.

MILLIKEN, W.; ALBERT, B. The use of medicinal plants by the Yanomami Indians of Brazil. Economic Botany, v. 50, p. 10-25, 1996.

MITCHELL, S.A.; AHMAD, M.H. A review of medicinal plant research at the University of the West Indies, Jamaica, 1948-2001. West Indian Medical Journal, v. 55, p. 243-269, 2006.
MORAIS, S.M.; PEREIRA, J.D.; DANTAS, J.D.P.; SILVA, A.R.A.; MAGALHÃES, E.F.M. Plantas medicinais usadas pelos índios Tapebas do Ceará. Revista Brasileira de Farmacognosia, v. 15, p. 169-177, 2005.

MORE, G.; TSHIKALANGE, T.E.; LALL, N.; BOTHA, F.; MEYER, J.J.M. Antimicrobial activity of medicinal plants against oral microorganisms. Journal of Ethnopharmacology, v. 119, p. 473-477, 2008.

MUHAMMAD, S.; LAWAL, M.T. Oral hygiene and the use of plants. Science Research Essays, v.5, p. 17881795, 2010.

MUTHU, C.; AYYANAR, M., RAJA, N.; IGNACIMUTHU, $S$. Medicinal plants used by traditional healers in Kancheepuram District of Tamil Nadu, India. Journal of Ethnobiology and Ethnomedicine, v. 2, p. 2-10, 2006.

NALINA, T.; RAHIM, Z.H.A. The crude aqueous extract of Piper betle and its antibacterial effect towards Streptococcus mutans. American Journal of Biochemistry and Biotechnology, v.3, p. 10-15, 2007.

NOGUEIRA, M.A.; DIAZ, M.G.; TAGAMI, P.M.; LORSCHEIDE, J. Atividade antimicrobiana de óleos essenciais e extratos de própolis sobre bactérias cariogênicas. Revista de Ciências Farmacêuticas Básica e Aplicada, v. 28, p. 93-97, 2007.

OLIVEIRA, E.O.S.; COLLIER, K.F.S.; MOTA, G.M.F.; ELY, B.P.; PEREIRA, F.R. Plantas medicinais usadas pela comunidade Kalunga do Quilombo do Engenho de Dentro em Cavalcante - GO, para tratamento de afecções bucais. Revista Cereus, v. 4, p. 2-10, 2011.

OLIVEIRA, F.C.S.; BARROS, R.F.M.; MOITA NETO, J.M. Plantas medicinais utilizadas em comunidades rurais de Oeiras, semiárido piauiense. Revista Brasileira de Plantas Medicinais, v. 12, p. 282-301, 2010.

OSTROSKY, E.A.; MIZUMOTO, M.K.; LIMA, M.E.L.; KANEKO, T.M.; NISHIKAWA, S.O.; FREITAS, B.R. Métodos para avaliação da atividade antimicrobiana e determinação da Concentração Mínima Inibitória (CMI) de plantas medicinais. Revista Brasileira de Farmacognosia, v. 18, p. 301-307, 2008.

PARK, K.M.; YOU, J.S.; LEE, H.Y.; BAEK, N.I.; HWANG, J.K. Kuwanon G: an antibacterial agent from the root bark of Morus alba against oral pathogens. Journal of Ethnopharmacology, v. 84, p. 181-185, 2003.

PASCARELLI, B.M.O.; ROCHA, M.E.N.; FRUTUOSO, V.S. Plantas Medicinais: da natureza ao medicamento. In: Pereira IB, Rolo M, Tomás LG. Iniciação científica na educação profissional em saúde: articulando trabalho, ciência e cultura. RJ: EPSJV: p. p. 93-109, 2006.

PAU, A.K.; CROUCHER, R.; MARCENES, W. Perceived inability to cope and care-seeking in patients with toothache: a qualitative study. Brazilian Dental Journal, v. 189 , p. 503-506. 2000.

PAU, A.K.; CROUCHER, R.; MARCENES, W. Prevalence estimates and associated factors for dental pain: a review. Oral Health Preventive Dentistry, v.1, p. 209220, 2003.

PEREIRA, J.V.; BERGAMO, D.C.B.; PEREIRA, J.O.; FRANÇA, S.C.; PIETRO, R.C.L.R.; SILVA, Y.T.C.S. Antimicrobial activity of Arctium lappa constituents against microorganisms commonly founding in endodontic infections. Brazilian Dental Journal, v. 16, p. 192-196, 2005.

PEREIRA, J.V.; PEREIRA, M.S.V.; SAMPAIO, F.C.; 
SAMPAIO, M.C.C.; ALVES, P.M.; ARAÚJO, C.R.F.; HIGINO, J.S. Efeito antibacteriano e antiaderente in vitro do extrato da Punica granatum Linn. sobre microrganismos do biofilme dental. Revista Brasileira de Farmacognosia, v.16, p. 88-93, 2006.

PRABU, G.R.; GNANAMANI, A.; SADULLA, S. Guaijaverin - a plant flavonoid as potential antiplaque agent against Streptococcus mutans. Journal of Applied Microbiology, v. 101, p. 487-495, 2006.

PRASHANT, G.M.; CHANDU, G.N.; MURULIKRISHNA, K.S.; SHAFIULLA, M.D. The effect of mango and neem extract on four organisms causing dental caries: Streptococcus mutans, Streptococcus salivarius, Streptococcus mitis and Streptococcus sanguis: an in vitro study. Indian Journal of Dental Research, v. 18, 148-151, 2007.

RITTER, M.R.; SOBIERAJSKI, G.R.; SCHENKEL, E.P.; MENTZ, L.A. Plantas usadas como medicinais no município de Ipê, RS, Brasil. Revista Brasileira de Farmacognosia, v. 12, p. 51-62, 2002.

RIVERO-CRUZ, J.F.;, SÁNCHEZ-NIETO, S.; BENÍTEZ, G.; CASIMIRO, X.; ALVARADO, C.I.; MOLINA, A.R.; RIVERO-CRUZ, B. Antibacterial compounds isolated from Byrsonima crassifolia. Revista Latinoamericana de Química, v.37, p. 155-163, 2009.

RODRIGUES, V.E.G.; CARVALHO, D.A. Levantamento etnobotânico de plantas medicinais no domínio do cerrado na região do alto Rio Grande - Minas Gerais. Ciência e Agrotecnologia, v. 25, p. 102-123, 2001.

RUKAYADI, Y.; HWANG, J.K. In vitro activity of xanthorrhizol against Streptococcus mutans biofilms. Letters in Applied Microbiology, v. 42, p. 400-404, 2006.

SAMARÃO, S.S.; CORRÊA, L.A.S.; MOREIRA, A.S.N.; FREIRE, M.G.M.; MACEDO, M.L.R. Estudo in vitro da atividade do extrato etanólico de sementes de bacupari (Rheedia gardneriana Planch. \& Triana) e das frações no crescimento de Streptococcus mutans. Revista Brasileira de Plantas Medicinais,v. 12, p. 234-238, 2010.

SAMPAIO, F.C.; PEREIRA, M.S.; DIAS, C.S.; COSTA, V.C.; CONDE, N.C.; BUZALAF, M.A. In vitro antimicrobial activity of Caesalpinia ferrea Martius fruits against oral pathogens. Journal of Ethnopharmacology, v.124, p. 289-294, 2009.

SANTANA, D.L.; PREZA, D.L.C.; ASSIS, J.G.A.; GUEDES, M.L.S. Plantas com propriedades terapêuticas utilizadas na comunidade de Campos, Amélia Rodrigues, Bahia, Brasil. Magistra, v. 20, 218-230, 2008.

SANTOS, E.B.; DANTAS, G.S,; SANTOS, H.B.; DINIZ, M.F.F.M.; SAMPAIO, F.C. Estudo etnobotânico de plantas medicinais para problemas bucais no município de João Pessoa, Brasil. Revista Brasileira de Farmacognosia, v. 19, p. 321-324, 2009a.

SANTOS, E.B.; SLUSARZ, P.A.A.; KOZLOWSKI JÚNIOR, V.A.; SCHWARTZ, J.P. Eficácia antimicrobiana de produtos naturais frente a microrganismos causadores da endocardite bacteriana. Publicatio UEPG: Ciências Biológicas e da Saúde v. 13, p. 67-72, 2007.

SANTOS, V.R.; GOMES, R.T.; OLIVEIRA, R.R.; CORTÉS, M.E.; BRANDÃO, M.G.L. Susceptibility of oral pathogenic microorganisms to aqueous and ethanolic extracts of Stryphnodendron adstringens (barbatimão). International Journal of Dentistry, v. 8, p. 1-5, 2009b.
SEVERINO, V.G.P.; et al.. Determination of antibacterial activity of crude extracts and compounds isolated from Hortia Oreadica (Rutaceae) against oral pathogens. Brazilian Journal of Microbiology, v.40, p. 535-540, 2009.

SHARMA, M.C.; SHARMA, S. Pharmacognostic and phytochemical screening of Vernonia amyggalina Linn against selected bacterial strains. Middle East Journal of Scientific Research, v. 6, 440-444, 2010.

SHARMA, S.; et al.. Evaluation of the antimicrobial, antioxidant, and anti-inflammatory activities of hydroxychavicol for its potential use as an oral care agent. Antimicrobial Agents and Chemotherapy, v. 53, p. 216-22, 2009.

SHEPHERD, M.A.; NADANOVSKY, P.; SHEIHAM, A. The prevalence and impact of dental pain in 8-year-old school children in Harrow, England. Brazilian Dental Journal, v. 187, p. 38-41, 1999.

SILVA, M.A.S.; SILVA, M.A.R.; HIGINO, J.S.; PEREIRA, M.S.V.; CARVALHO, A.A.T. Atividade antimicrobiana e antiaderente in vitro do extrato de Rosmarinus officinalis Linn. sobre bactérias orais planctônicas. Revista Brasileira de Farmacognosia, v. 18, p. 236-240, 2008.

SIMÕES, C.O.M.; SCHENKEL, E.P.; GOSMANN, G.; MELLO, J.C.P.; MENTZ, L.A.; PETROVICK, P.R. Farmacognosia: da planta ao medicamento. Porto Alegre/Florianópolis: Editora da UFSC. 5a ed., UFRGS Editora, 467 p., 2004.

SMITH, A.J.; ROBERTSON, D.; TANG, M.K.; JACKSON, M.S.; MACKENZIE, D.; BAGG, J. Staphylococcus aureus in the oral cavity: a three-year retrospective analysis of clinical laboratory data. Brazilian Dental Journal, v. 195, p. 701-703, 2003.

SOARES, D.G.S.; OLIVEIRA, C.B.; LEAL, C.; DRUMOND, M.R.S.; PADILHA, W.W.N. Atividade antibacteriana in vitro da tintura de aroeira (Schinus terebinthifolius) na descontaminação de escovas dentais contaminadas pelo S. mutans. Pesquisa Brasileira de Odontopediatria Clínica integrada, v. 7, p. 253-257, 2007.

SOARES, S.P.; VINHOLIS, A.H.C.; CASEMIRO, L.A.; SILVA, M.L.A.; CUNHA, W.R.; MARTINS, C.H.G. Atividade antibacteriana do extrato hidroalcoólico bruto de Stryphnodendron adstringens sobre microrganismos da cárie dental. Revista Odonto Ciência, v. 23, p. 141-144, 2008.

SONG, J.H.; YANG, T.C.; CHANG, K.W.; HAN, S.K.; YI, H.K.; JEON, J.G. In vitro anti-cariogenic activity of dichloromethane fraction from Rheum undulatum $\mathrm{L}$. root. Archives of Pharmacal Research, v.29, p. 490496, 2006.

SOUZA, C.D.; FELFILI, J.M. Uso de plantas medicinais na região de Alto Paraíso de Goiás, GO, Brasil. Acta Botanica Brasilica, v. 20, p. 135-142, 2006.

SOUZA, E.L.B.; LOPES, J.C.A.; GASPAR JUNIOR, A.A.; SILVA, K.L.M.; SILVA, E.F.; GASPAR, G.S. A doença periodontal como fator de risco para as doenças cardiovasculares. International Journal of Dentistry, v. 1, p. 1-6, 2006.

SUDDHASTHIRA, T.; THAWEBOON, S.; DENDOUNG, N.; THAWEBOON, B.; DECHKUNAKORN, S. Antimicrobial activity of Cratoxylum formosum on Streptococcus mutans. The Southeast Asian Journal of Tropical Medicine and Public Health, v. 37, p. 1156-1159, 2006. 
TAKARA, T.; USHIJIMA, K.; WADA, K.; IWASAKI, H.; YAMASHITA, M. Phenolic compounds from sugarcane molasses possessing antibacterial activity against cariogenic bacteria. The Journal of Oleo Science, v. 56, p. 611-614, 2007.

TAPSOBA, H.; DESCHAMPS, J.P. Use of medicinal plants for the treatment of oral diseases in Burkina Faso. Journal of Ethnopharmacology, v. 104, p. 6878, 2006.

TAVARES, W.L.F.; APOLÔNIO, A.C.M.; GOMES, R.T.; TEIXEIRA, K.I.R.; BRANDÃO, M.G.L.; SANTOS, V.R. Assessment of the antimicrobial activity of Casearia sylvestris extract against oral pathogenic microorganisms. Revista de Ciências Farmacêuticas Básica e Aplicada, v. 29, p. 257-260, 2009.

THAWEBOON, S.; THAWEBOON, B. In vitro antimicrobial activity of Ocimum americanum L. essential oil against oral microorganisms. The Southeast Asian Journal of Tropical Medicine and Public Health, v. 40, p. 1025-33, 2009.

THOMPSON, R.C.A.; MELONI, B.P. Molecular variation in Giardia. Acta Tropica, v. 53, p. 167-184, 1993.
VADLAPUDI, V.; NAIDU, K.C.. Bioactivity of marine mangrove plant Avicennia alba on selected plant and oral pathogens. International Journal of ChemTech Research, v. 1, p. 1213-1216. 2009

VENDRUSCOLO, G.S.; MENTZ, L.A. Estudo da concordância das citações de uso e importância das espécies e famílias utilizadas como medicinais pela comunidade do bairro Ponta Grossa, Porto Alegre, RS, Brasil. Acta Botanica Brasilica, v. 20, p. 367-382, 2006.

YANTI, RUKAYADI, Y.; LEE, K.H.; HWANG, J.K. Activity of panduratin A isolated from Kaempferia pandurata Roxb. against multi-species oral biofilms in vitro. Journal of Oral Science, v.5, p. 87-95, 2009.

YIM, N.H.; HA, D.T.; TRUNG, T.N.; KIM, J.P.; LEE, S.; NA, M.; JUNG, H.; KIM, H.S.; KIM, Y.H.; BAE, K. The antimicrobial activity of compounds from the leaf and stem of Vitis amurensis against two oral pathogens. Bioorganic \& Medicinal Chemistry Letters, v. 20, p. 11651168, 2010.

YUNES, R.A.; CALIXTO, J.B. 2001. (orgs.) Plantas Medicinais sob a Ótica da Química Medicinal Moderna. Chapecó: Argos. 